\title{
A Simple and Modular Strategy for Small Molecule Synthesis: Iterative Suzuki- Miyaura Coupling of $B$-Protected Haloboronic Acid Building Blocks
}

\author{
Eric P. Gillis and Martin D. Burke* \\ Department of Chemistry, University of Illinois at Urbana-Champaign, Urbana, IL 61801
}

\section{Supporting Information}

Part A

Part B

$\begin{array}{rll}\text { I. } & \text { General methods } & \text { S1-S2 } \\ \text { II. } & \text { Synthesis of boronate esters (Table 1) } & \text { S3-S6 } \\ \text { III. } & \text { Competition studies (Table 1) } & \text { S7 } \\ \text { IV. } & \text { Synthesis of haloboronate esters (Scheme 1) } & \text { S8-S13 } \\ \text { V. } & \text { Selective Suzuki-Miyaura coupling with haloboronate esters (Table 2) } & \text { S14-S18 } \\ \text { VI. } & \text { Deprotection of boronate esters (Table 2) } & \text { S19-S22 } \\ \text { VII. } & \text { Total synthesis of ratanhine (Scheme 3) } & \text { S23-S39 }\end{array}$

VIII. NMR spectra

Part C

IX. X-ray data for $8 \mathrm{e}(. \mathrm{cif}$ file)

Complete versions of truncated references

(4) (a) Zhang, J.; Moore, J.S.; Xu, Z.; Aguirre, R.A. J. Am. Chem. Soc. 1992, 114, 2273-2274. (b) Young, J.K.; Nelson, J.C.; Moore, J.S. J. Am. Chem. Soc. 1994, 116, 10841-10842.

(6) (a) Barder, T.E.; Walker, S.D.; Martinelli, J.R.; Buchwald, S.L. J. Am. Chem. Soc. 2005, 127, 4685-4696. (b) Billingsley, K.; Buchwald, S.L. J. Am. Chem. Soc. 2007, 129, 3358-3366. (c) Littke, A.F.; Dai, C.; Fu, G.C. J. Am. Chem. Soc. 2000, 122, 4020-4028. (d) Nicolaou, K.C.; Bulger, P.G.; Sarlah, D. Angew. Chem. Int. Ed. 2005, 44, 4442-4489.

(12) Related aryl- and alkyl boronate esters have been described: (a) Mancilla, T.; Contreras, R. J. Organomet. Chem. 1986,

307, 1-6. (b) Mancilla, T.; Zamudio-Rivera, L.S.; Beltram, H.I.; Santillan, R.; Farfan, N. Arkivoc 2005, 366-376. (c)

Contreras, R.; García, C.; Mancilla, T. J. Organomet. Chem. 1983, 246, 213-217.

(14) Arnone, A.; Modugno, V.D.; Nasini, G.; de Pava, O.V. Gazetta Chimica Italiana, 1990, 120, $397-401$.

(17) Kirchhoff, J.H.; Netherton, M.R.; Hills, I.D.; Fu, G.C. J. Am. Chem. Soc. 2002, 124, 13662-13663.

\section{General Methods}

Materials. Commercial reagents were purchased from Sigma-Aldrich, Fisher Scientific, Alfa Aesar, Lancaster Synthesis, or Frontier Scientific, and were used without further purification unless otherwise noted. N-Bromosuccinimide and 4-butylphenylboronic acid were recrystallized from hot water prior to use. Solvents were purified via passage through packed columns as described by Pangborn and coworkers ${ }^{1}$ (THF, $\mathrm{Et}_{2} \mathrm{O}, \mathrm{CH}_{3} \mathrm{CN}, \mathrm{CH}_{2} \mathrm{Cl}_{2}$ : dry neutral alumina; hexane, benzene, and toluene, dry neutral alumina and Q5 reactant; DMSO, DMF: activated molecular sieves). Water was double distilled. Triethylamine, diisopropylamine, diethylamine, pyridine, and 2,6-lutidine were freshly distilled under an atmosphere of nitrogen from $\mathrm{CaH}_{2}$. The following compounds were prepared according to literature precedent: $\quad \mathrm{N}$-isopropyliminodiacetic acid, $^{2}$ (E)-3-bromostyrylboronic acid, ${ }^{3}$ 5-bromo-2-

\footnotetext{
${ }^{1}$ Pangborn, A.B.; Giardello, M.A; Grubbs, R.H.; Rosen, R.K.; Timmers, F.J. Organometallics 1996, 15, $1518-1520$.

2 (a) Stein, A.; Gregor, H.P.; Spoerri, P.E. J. Am. Chem. Soc. 1955, 77, 191-192. (b) Dubé, C. E.; Mukhopadhyay, S.; Bonitatebus, P. J.; Staples, R. J.; Armstrong, W. H., Inorg. Chem., 2005, 44, 5161-5175.

${ }^{3}$ Perner, R.J. and coworkers, Biorg. Med. Chem. Lett. 2005, 15, 2803-2807.
} 
benzofuranylboronic acid, ${ }^{4}$ 2-bromo-5-methoxyphenol, ${ }^{5}$ 4-(methoxymethoxy)benzoic acid. ${ }^{6}$ Solutions of $n$-butyllithium were titrated according to the method of Hoye and coworkers.

General Experimental Procedures. Suzuki-Miyaura cross-coupling reactions were typically performed under an atmosphere of argon in oven- or flame-dried I-Chem or Wheaton vials sealed with PTFE-lined plastic caps. All other reactions were performed in oven- or flame-dried round-bottom or modified Schlenk flasks fitted with rubber septa under a positive pressure of argon or nitrogen unless otherwise indicated. Organic solutions were concentrated via rotary evaporation under reduced pressure. Reactions were monitored by analytical thin layer chromatography (TLC) performed using the indicated solvent on E. Merck silica gel 60 F254 plates $(0.25 \mathrm{~mm})$. Compounds were visualized by exposure to a UV lamp ( $\lambda$ $=254 \mathrm{~nm}$ ), a glass chamber containing iodine, and/or a solution of $\mathrm{KMnO}_{4}$, an acidic solution of $\mathrm{p}$ anisaldehyde, or a solution of ceric ammonium molybdate (CAM) followed by brief heating using a Varitemp heat gun. Flash column chromatography was performed as described by Still and coworkers ${ }^{8}$ using EM Merck silica gel 60 (230-400 mesh).

Structural analysis. ${ }^{1} \mathrm{H}$ NMR spectra were recorded at $23{ }^{\circ} \mathrm{C}$ on one of the following instruments: Varian Unity 400, Varian Unity 500, Varian Unity Inova 500NB. Chemical shifts $(\delta)$ are reported in parts per million ( $\mathrm{ppm}$ ) downfield from tetramethylsilane and referenced to residual protium in the NMR solvent $\left(\mathrm{CHCl}_{3}, \delta=7.26 ; \mathrm{CD}_{2} \mathrm{HCN}, \delta=1.93\right.$, center line $)$ or to added tetramethylsilane $(\delta=0.00)$. Data are reported as follows: chemical shift, multiplicity $(\mathrm{s}=$ singlet, $\mathrm{d}=$ doublet, $\mathrm{t}=$ triplet, $\mathrm{q}=$ quartet, sept $=$ septet, $\mathrm{m}=$ multiplet, $\mathrm{b}=$ broad, app $=$ apparent $)$, coupling constant $(J)$ in $\operatorname{Hertz}(\mathrm{Hz})$, and integration. ${ }^{13} \mathrm{C}$ NMR spectra were recorded at $23{ }^{\circ} \mathrm{C}$ on one of the following instruments: Varian Unity 500 or Varian Unity Inova 500NB. Chemical shifts $(\delta)$ are reported in ppm downfield from tetramethylsilane and referenced to carbon resonances in the NMR solvent $\left(\mathrm{CDCl}_{3}, \delta=77.0\right.$, center line; $\mathrm{CD}_{3} \mathrm{CN}, \delta=1.30$, center line) or to added tetramethylsilane $(\delta=0.00)$. Carbons bearing boron substituents were not observed (quadrupolar relaxation). ${ }^{11} \mathrm{~B}$ NMR were recorded using a General Electric GN300WB instrument and referenced to an external standard of $\left(\mathrm{BF}_{3} \bullet \mathrm{Et}_{2} \mathrm{O}\right)$. High resolution mass spectra (HRMS) were performed by Furong Sun and Dr. Steve Mullen at the University of Illinois School of Chemical Sciences Mass Spectrometry Laboratory. Infrared spectra were collected from a thin film on $\mathrm{NaCl}$ plates on a Mattson Galaxy Series FTIR 5000 spectrometer with internal referencing. Absorption maxima $\left(v_{\max }\right)$ are reported in wavenumbers $\left(\mathrm{cm}^{-1}\right)$. X-ray crystallographic analysis of 8 e was carried out by Dr. Scott Wilson at the University of Illinois George L. Clark X-Ray facility.

\footnotetext{
${ }^{4}$ Friedman, M. R.; Toyne, K. J.; Goodby, J. W.; Hird, M., J. Mater. Chem., 2001, 11, 2759 - 2772.

${ }^{5}$ Albert, J. S.; Aharony, D.; Andisik, D.; Barthlow, H.; Bernstein, P. R.; Bialecki, R. A.; Dedinas, R.; Dembofsky, B. T.; Hill, D.; Kirkland, K.; Koether, G. M.; Kosmider, B. J.; Ohnmacht, C.; Palmer, W.; Potts, W.; Rumsey, W.; Shen, L.; Shenvi, A.; Sherwood, S.; Warwick, P. J.; and Russell, K., J. Med. Chem., 2002, 45, 3972-3983.

${ }^{6}$ Lampe, J.W. and coworkers, J. Med. Chem. 2002, 45, 2624-2643.

${ }^{7}$ Hoye, T. R.; Eklov, B. M.; Voloshin, M. Org. Lett., 2004, 6, 2567-2570.

${ }^{8}$ Still, W.C.; Kahn, M.; Mitra, A.; J. Org. Chem. 1978, 43, 2923-2925.
} 


\section{Synthesis of boronate esters (Table 1)}

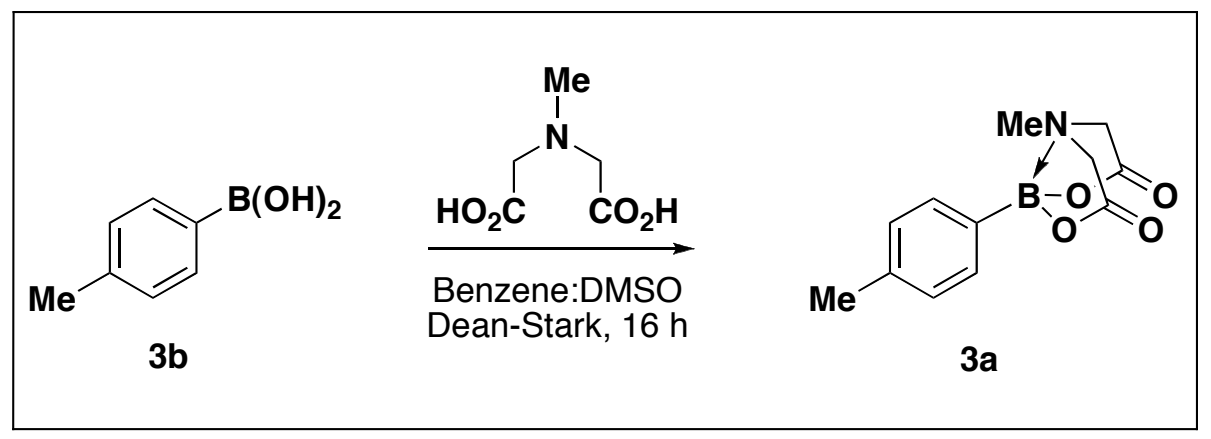

Boronate ester 3a. A $500 \mathrm{~mL}$ flask was charged with $p$-tolylboronic acid (3.00 g, $22.1 \mathrm{mmol}, 1$ equiv.), $\mathrm{N}$-methyliminodiacetic acid (3.25 g, $22.1 \mathrm{mmol}, 1$ equiv.), benzene (360 mL) and DMSO (40 mL). The flask was fitted with a Dean-Stark trap and a reflux condenser, and the mixture was refluxed with stirring for $16 \mathrm{~h}$ followed by concentration in vacuo. The resulting crude product was adsorbed onto Florisil gel from a MeCN solution. The resulting powder was dry-loaded on top of a silica gel column slurry-packed with EtOAc. The product was eluted using a gradient (EtOAc $\rightarrow$ EtOAc:MeCN 2:1) to yield boronate ester 3a as a colorless, crystalline solid (5.05 g, 93\%).

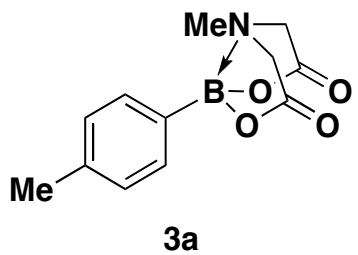

TLC (EtOAc)

$\mathrm{R}_{\mathrm{f}}=0.40$, stained by $\mathrm{KMnO}_{4}$

${ }^{1} \mathrm{H}-\mathrm{NMR}\left(500 \mathrm{MHz}, \mathrm{CD}_{3} \mathrm{CN}\right)$

$\delta 7.37(\mathrm{~d}, J=8 \mathrm{~Hz}, 2 \mathrm{H}), 7.20(\mathrm{~d}, J=8 \mathrm{~Hz}, 2 \mathrm{H}), 4.05(\mathrm{~d}, J=17 \mathrm{~Hz}, 2 \mathrm{H}), 3.87(\mathrm{~d}, J=17 \mathrm{~Hz}, 2 \mathrm{H})$, $2.47(\mathrm{~s}, 3 \mathrm{H}), 2.33(\mathrm{~s}, 3 \mathrm{H})$.

${ }^{13} \mathrm{C}-\mathrm{NMR}\left(125 \mathrm{MHz}, \mathrm{CD}_{3} \mathrm{CN}\right)$

ठ 169.6, 140.0, 133.4, 129.6, 62.7, 48.4, 21.4.

${ }^{11} \mathrm{~B}-\mathrm{NMR}\left(100 \mathrm{MHz}, \mathrm{CD}_{3} \mathrm{CN}\right)$

$\delta 12.2$

HRMS (EI+)

Calculated for $\mathrm{C}_{12} \mathrm{H}_{14} \mathrm{O}_{4} \mathrm{NB}(\mathrm{M})^{+}: \quad 247.1016$

Found:

247.1014

IR (thin film, $\mathrm{cm}^{-1}$ )

$3046,3023,3003,2958,2917,1746,1612,1454,1424,1397,1335,1257,1243,1188,1150$, 1038, 1012, 993, 961, 867, 807, 786, 650, 638. 
The following data are consistent with the assignment of $\mathbf{3 a}$ as an sp ${ }^{3}$-hybridized boronate ester.

1. ${ }^{1} \mathrm{H}$ NMR: The diastereotopic methylene protons of 3a appear as a well-resolved pair of doublets at $\delta$ 4.05 and 3.87 with a large geminal coupling constant of $17 \mathrm{~Hz}$. This is consistent with literature precedent for related conformationally-rigid arylboronate ester complexes.. ${ }^{9}$ One such complex has been characterized unambiguously by single crystal X-ray diffraction analysis. ${ }^{10}$

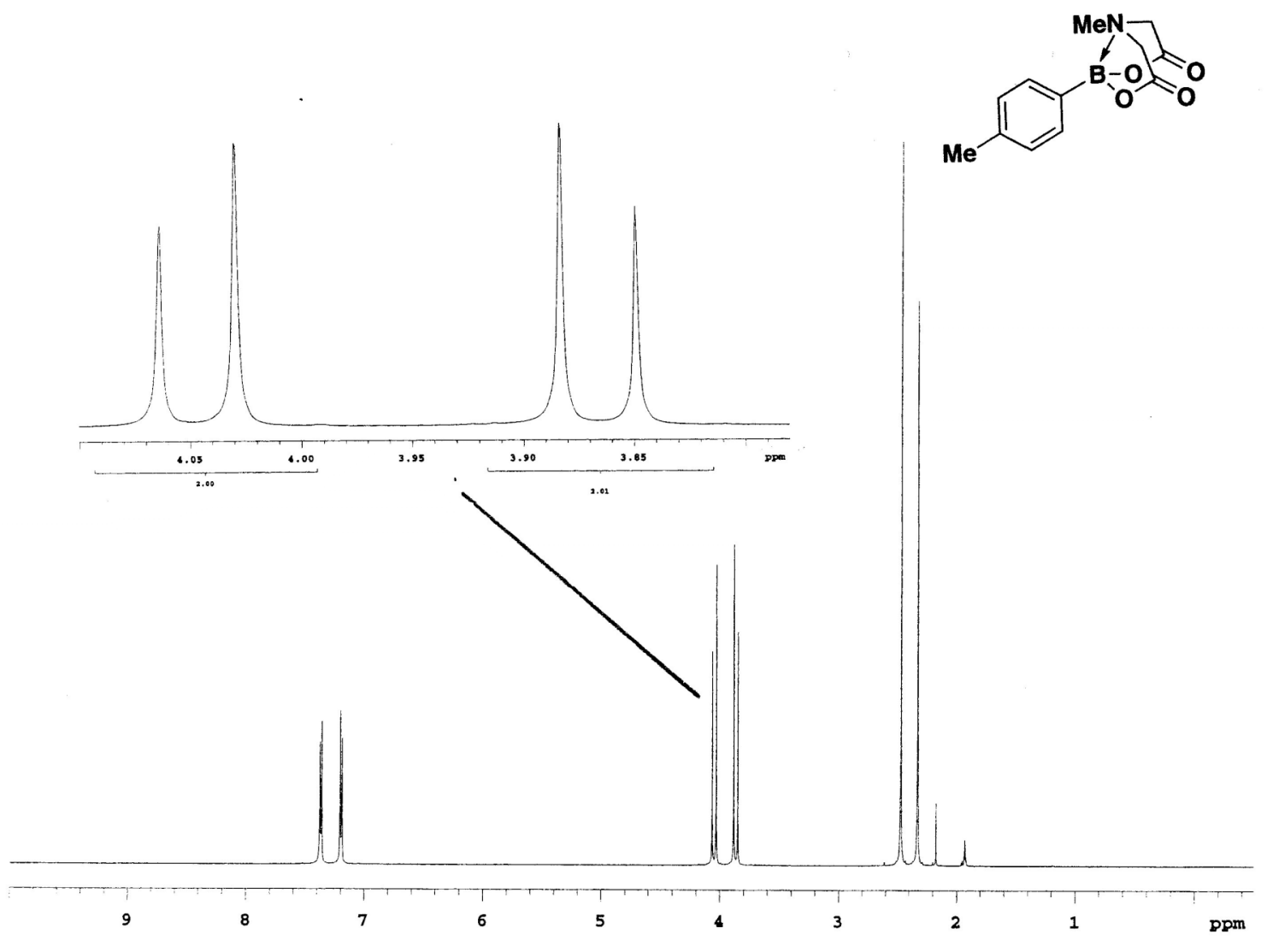

2. ${ }^{11}$ B NMR: Boron NMR spectroscopy is a well-established method for probing the structure of boronic acids and boronate ester complexes. ${ }^{11}$ The ${ }^{11} \mathrm{~B}$ NMR spectra for $p$-tolyboronic acid and 3a demonstrate chemical shifts of $\delta 29.6$ and $\delta 12.2$, respectively. These data are consistent with the assignment of 3a as a pyramidalized boronate ester.

3. These same diagnostic ${ }^{1} \mathrm{H}$ and ${ }^{11} \mathrm{~B}$ NMR signals are observed for the vinylic haloboronate ester $8 \mathbf{e}$. We have obtained an X-ray structure of this compound (Scheme 1) which confirmed unambiguously the $\mathrm{sp}^{3}$ hybridization of the boron center.

\footnotetext{
${ }^{9}$ Mancilla, T.; Contreras, R. J. Organomet. Chem. 1986, 307, 1-6.

${ }^{10}$ Mancilla, T. and coworkers, Arkivoc 2005, 366-376.

${ }^{11}$ Zhu, L.; Shabbir, S.H.; Gray, M.; Lynch, V.M.; Sorey, S.; Anslyn, E.V. J. Am. Chem. Soc. 2006, 128, $1222-1232$.
} 


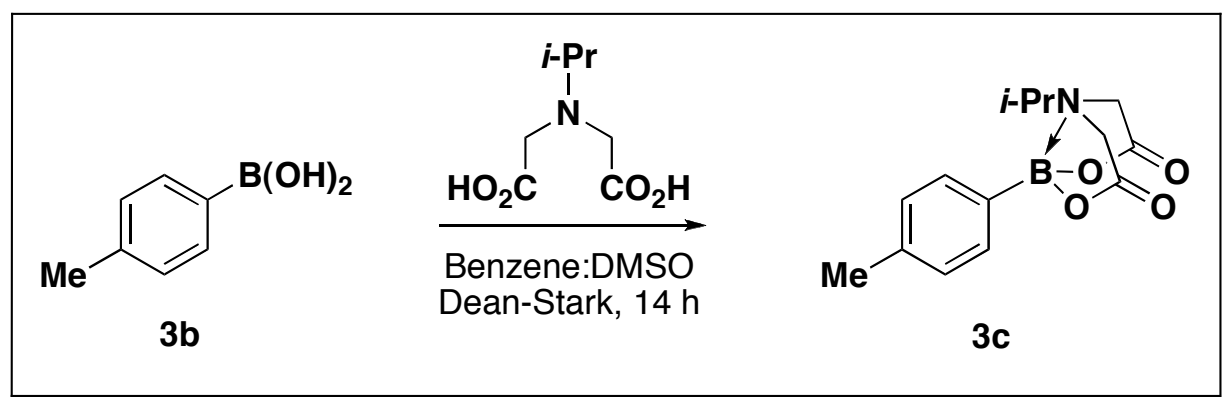

Boronate ester 3c. In an unoptimized procedure, a $250 \mathrm{~mL}$ roundbottom flask was charged with $p$ tolylboronic acid (7.36 mmol, $1.00 \mathrm{~g}), N$-isopropyliminodiacetic acid (7.36 mmol, $1.29 \mathrm{~g})$, benzene (150 $\mathrm{mL})$ and DMSO $(15 \mathrm{~mL})$. The flask was fitted with a Dean-Stark trap and a reflux condenser, and the mixture was refluxed with stirring for $14 \mathrm{~h}$ and then concentrated in vacuo. Purification by flash chromatography $\left(\mathrm{Et}_{2} \mathrm{O} \rightarrow \mathrm{Et}_{2} \mathrm{O}: \mathrm{MeCN} 1: 2\right)$ yielded boronate ester 3c as a colorless, crystalline solid (747 $\mathrm{mg}, 37 \%)$.

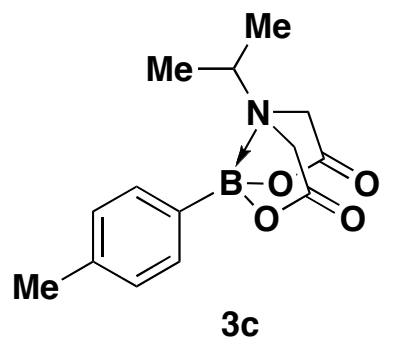

TLC (EtOAc)

$\mathrm{R}_{\mathrm{f}}=0.36$, stained by $\mathrm{KMnO}_{4}$

${ }^{1} \mathrm{H}-\mathrm{NMR}\left(500 \mathrm{MHz}, \mathrm{CD}_{3} \mathrm{CN}\right)$

$\delta 7.40(\mathrm{~d}, J=8 \mathrm{~Hz}, 2 \mathrm{H}), 7.19(\mathrm{~d}, J=8 \mathrm{~Hz}, 2 \mathrm{H}), 4.05(\mathrm{~d}, J=17 \mathrm{~Hz}, 2 \mathrm{H}), 3.81(\mathrm{~d}, J=17 \mathrm{~Hz}, 2 \mathrm{H})$,

3.06 (sept, $J=6.5 \mathrm{~Hz}, 1 \mathrm{H}), 2.33(\mathrm{~s}, 3 \mathrm{H}), 1.05(\mathrm{~d}, J=6.5 \mathrm{~Hz}, 6 \mathrm{H})$.

${ }^{13} \mathrm{C}-\mathrm{NMR}\left(125 \mathrm{MHz}, \mathrm{CD}_{3} \mathrm{CN}\right)$

$\delta 169.8,139.9,133.6,129.5,59.8,57.2,21.4,17.2$.

${ }^{11} \mathrm{~B}-\mathrm{NMR}\left(100 \mathrm{MHz}, \mathrm{CD}_{3} \mathrm{CN}\right)$

$\delta 11.96$

HRMS (EI+)

Calculated for $\mathrm{C}_{14} \mathrm{H}_{18} \mathrm{O}_{4} \mathrm{NB}(\mathrm{M})^{+}$: $\quad 275.1329$

Found:

275.1331

IR (thin film, $\mathrm{cm}^{-1}$ )

3011, 2951, 1761, 1744, 1727, 1312, 1240, 1048, 1021, 982, 862, 808. 


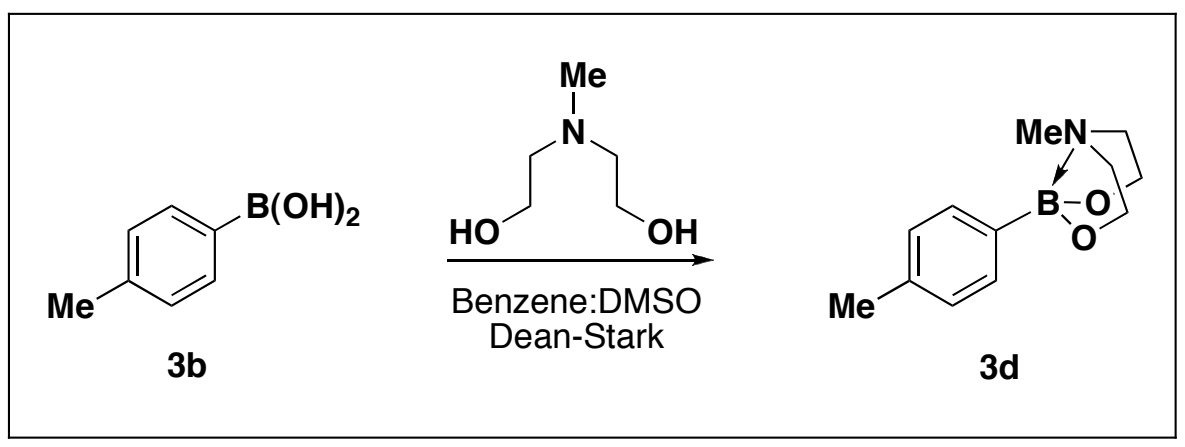

Boronate ester 3d. In an unoptimized procedure, a $100 \mathrm{~mL}$ roundbottom flask was charged with $p$ tolylboronic acid (3.68 mmol, $500 \mathrm{mg}), N$-methyldiethanolamine $(3.68 \mathrm{mmol}, 422 \mu \mathrm{L})$ and toluene $(70$ $\mathrm{mL})$. The flask was fitted with a Dean-Stark trap and a reflux condenser, and the solution was refluxed with stirring for $8 \mathrm{~h}$ and then allowed to cool to $23{ }^{\circ} \mathrm{C} . \mathrm{CaCl}_{2}$ (app. $200 \mathrm{mg}$, a fine powder) and $\mathrm{NaHCO}_{3}$ (app. $200 \mathrm{mg}$ ) were then added, and the resulting mixture was stirred for $15 \mathrm{~min}$. and then was filtered. The filtrate was concentrated in vacuo and residual solvent was removed via co-evaporation with $\mathrm{CH}_{2} \mathrm{Cl}_{2}$ to yield boronate ester 3d as a colorless, crystalline solid (399 mg, 50\%).

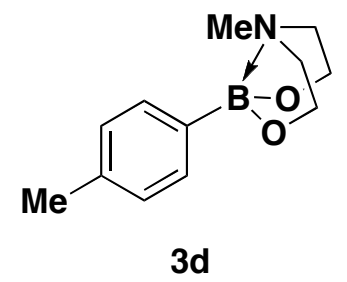

TLC

Compound is unstable to $\mathrm{SiO}_{2}$

${ }^{1} \mathrm{H} \mathrm{NMR}\left(500 \mathrm{MHz}, \mathrm{CD}_{3} \mathrm{CN}\right)$

$\delta 7.42(\mathrm{~d}, J=8 \mathrm{~Hz}, 2 \mathrm{H}), 7.07(\mathrm{~d}, J=8 \mathrm{~Hz}, 2 \mathrm{H}), 3.99(\mathrm{ddd}, J=10,8,5 \mathrm{~Hz}, 2 \mathrm{H}), 3.93$ (ddd, $J=10$, 6, $4 \mathrm{~Hz}, 2 \mathrm{H}$ ), 3.17 (ddd, $J=12,5,4 \mathrm{~Hz}, 2 \mathrm{H}), 2.93$ (ddd, $J=12,8,6 \mathrm{~Hz}, 2 \mathrm{H}), 2.28$ (s, 3H), 2.20 (s, $3 \mathrm{H})$.

${ }^{13} \mathrm{C}$ NMR $\left(125 \mathrm{MHz}, \mathrm{CD}_{3} \mathrm{CN}\right)$

$\delta 137.3,134.3,128.7,62.9,61.1,48.0,21.4$.

${ }^{11} \mathrm{~B}$ NMR (100 MHz, $\left.\mathrm{CD}_{3} \mathrm{CN}\right)$

$\delta 12.7$

HRMS (EI+)

Calculated for $\mathrm{C}_{12} \mathrm{H}_{18} \mathrm{O}_{2} \mathrm{NB}(\mathrm{M})^{+}: \quad 219.1431$

Found:

IR (thin film, $\mathrm{cm}^{-1}$ )

2999, 2948, 2911, 2873, 2830, 1606, 1455, 1370, 1338, 1280, 1250, 1222, 1193, 1181, 1150, 1097, 1035, 994, 944, 808, 786, 735, 718. 


\section{Competition studies (Table 1)}

Preparation of catalyst stock solution. In a glove box, to a vial equipped with a small stir bar and containing the 2-(di-tert-butylphosphino)biphenyl ligand was added a $0.02 \mathrm{M}$ solution of $\mathrm{Pd}(\mathrm{OAc})_{2}$ in THF in a volume sufficient to yield a $0.04 \mathrm{M}$ solution with respect to the phosphine ligand. The vial was sealed with a PTFE-lined cap, removed from the glove box, and maintained at $65^{\circ} \mathrm{C}$ with stirring for 30 $\min$.

Reaction setup. In a glove box, a glass vial equipped with a small stir bar was charged with boronate ester $3(0.06 \mathrm{mmol})$ and anhydrous $\mathrm{K}_{3} \mathrm{PO}_{4}$ as a finely ground powder $(32 \mathrm{mg}, 0.15 \mathrm{mmol})$. To this vial was then added a $250 \mu \mathrm{L}$ of a THF solution of 4-butylphenylboronic acid $(0.24 \mathrm{M}, 0.06 \mathrm{mmol})$, 4bromobenzaldehyde $(0.20 \mathrm{M}, 0.05 \mathrm{mmol})$ and biphenyl $(0.08 \mathrm{M}$, internal std. for HPLC analysis). Finally, to this same vial was added $50 \mathrm{uL}$ of the catalyst stock solution described above. The vial was then sealed with a PTFE-lined cap, removed from the glove box, and maintained in a $65^{\circ} \mathrm{C}$ oil bath with stirring for $12 \mathrm{~h}$. The reaction solution was then allowed to cool to $23{ }^{\circ} \mathrm{C}$ and filtered through a plug of silica gel, eluting with MeCN:THF 1:1. The filtrate was then analyzed by HPLC as described below.

Analysis. The ratio of products 5 and $\mathbf{6}$ was determined using an HPLC system (Agilent Technologies) fitted with a Waters SunFire Prep $\mathrm{C}_{18} 5 \mu \mathrm{m}$ column $(10$ x $250 \mathrm{~mm}$, Lot No. 156-160331) with a flow rate of $4 \mathrm{~mL} / \mathrm{min}$ and a gradient of $\mathrm{MeCN}: \mathrm{H}_{2} \mathrm{O} 5: 95 \rightarrow$ 95:5 over $23 \mathrm{~min}$., with UV detection at $268 \mathrm{~nm}$ (4bromobenzaldehyde, $\mathrm{t}_{R}=14.66$ min.; biphenyl, $\mathrm{t}_{R}=21.80$ min. $)$ and $293 \mathrm{~nm}\left(\mathbf{5}, \mathrm{t}_{R}=25.79\right.$ min.; 6, $\mathrm{t}_{R}=$ 20.50 min.; it was determined that the absorption coefficients for $\mathbf{5}$ and $\mathbf{6}$ at $293 \mathrm{~nm}$ are identical within the limits of experimental error).

Competition of 4-butylphenylboronic acid vs. boronate ester 3a (Entry 1). The general procedure was followed using $\mathbf{3 a}(0.06 \mathrm{mmol})$. The ratio of $\mathbf{5 : 6}$ was 24:1.0, average of 3 runs.

Competition of 4-butylphenylboronic acid vs. boronic acid 3b (Entry 2). The general procedure was followed using $\mathbf{3 b}(0.06 \mathrm{mmol})$. The ratio of 5:6 was 1.0:1.0, average of 3 runs.

Competition of 4-butylphenylboronic acid vs. boronate ester 3c (Entry 3). The general procedure was followed using $\mathbf{3 c}(0.06 \mathrm{mmol})$. The ratio of 5:6 was 26:1.0, average of 3 runs.

Competition of 4-butylphenylboronic acid vs. boronate ester 3d (Entry 4). The general procedure was followed using $\mathbf{3 d}(0.06 \mathrm{mmol})$. The ratio of 5:6 was 1.0:1.0, average of 3 runs. 
IV. Synthesis of haloboronate esters (Scheme 1).

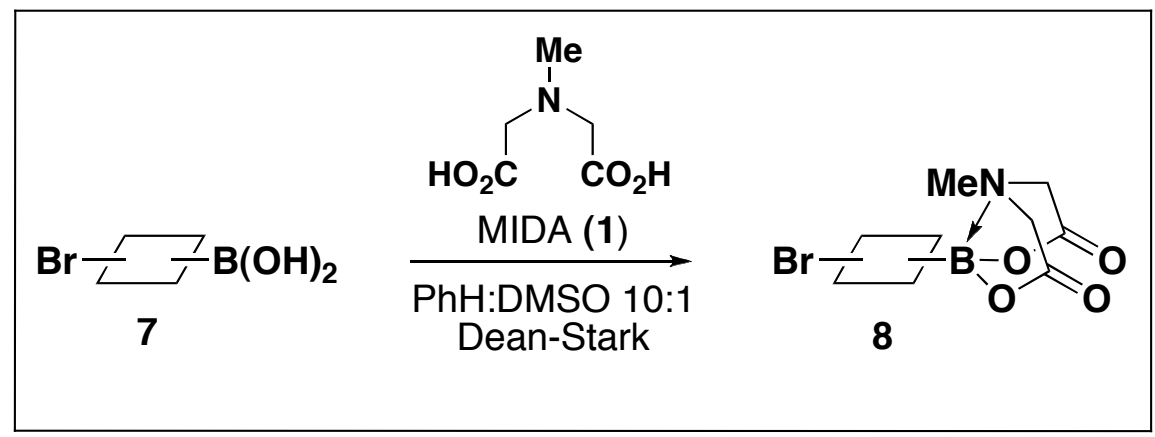

General procedure for the synthesis of haloboronate esters. A roundbottom flask equipped with a stir bar was charged with haloboronic acid (1 equiv.), $N$-methyliminodiacetic acid (1-1.5 equiv.), and benzene:DMSO (10:1). The flask was fitted with a Dean-Stark trap and a reflux condenser, and the mixture was refluxed with stirring for 12-18 hours. The reaction solution was allowed to cool to $23{ }^{\circ} \mathrm{C}$ and the solvent was removed in vacuo. The resulting crude solid was absorbed onto Florisil gel from a $\mathrm{MeCN}$ solution. The resulting powder was dry-loaded on top of a silica gel column slurry-packed with $\mathrm{Et}_{2} \mathrm{O}$. The column was flushed with a copious volume of $\mathrm{Et}_{2} \mathrm{O}$; the product was then eluted with a mixture of $\mathrm{Et}_{2} \mathrm{O}: \mathrm{MeCN}$. All products thus obtained were analytically pure, colorless, crystalline solids that were indefinitely bench stable at $23{ }^{\circ} \mathrm{C}$ under air.

Boronate ester 8a. The general procedure was followed using 4-bromophenylboronic acid (1.00 g, 4.98 mmol, 1 equiv.), N-methyliminodiacetic acid $(733 \mathrm{mg}, 4.98 \mathrm{mmol})$, benzene $(150 \mathrm{~mL})$ and DMSO (15 $\mathrm{mL}$ ). The mixture was refluxed for $12 \mathrm{~h}$. The product was eluted using a gradient; $\mathrm{Et}_{2} \mathrm{O} \rightarrow \mathrm{Et}_{2} \mathrm{O}: \mathrm{CH}_{3} \mathrm{CN}$ 1:1. The title compound was isolated as an analytically pure, colorless, crystalline solid (1.53 g, 98\%).

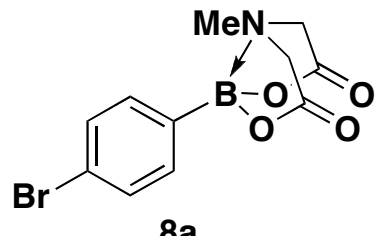

TLC (EtOAc)

$8 \mathbf{a}$

$\mathrm{R}_{\mathrm{f}}=0.36$, stained by $\mathrm{KMnO}_{4}$

${ }^{1} \mathrm{H}-\mathrm{NMR}\left(500 \mathrm{MHz}, \mathrm{CD}_{3} \mathrm{CN}\right)$

$\delta 7.53(\mathrm{~d}, J=8 \mathrm{~Hz}, 2 \mathrm{H}), 7.41(\mathrm{~d}, J=8 \mathrm{~Hz}, 2 \mathrm{H}), 4.07(\mathrm{~d}, J=17 \mathrm{~Hz}, 2 \mathrm{H}), 3.89(\mathrm{~d}, J=17 \mathrm{~Hz}, 2 \mathrm{H})$,

$2.50(\mathrm{~s}, 3 \mathrm{H})$.

${ }^{13} \mathrm{C}-\mathrm{NMR}\left(125 \mathrm{MHz}, \mathrm{CD}_{3} \mathrm{CN}\right)$

ठ $169.4,135.5,131.9,124.4,62.8,48.5$.

${ }^{11} \mathrm{~B}$ NMR $\left(100 \mathrm{MHz}, \mathrm{CD}_{3} \mathrm{CN}\right)$

$\delta 11.9$

HRMS (EI+)

Calculated for $\mathrm{C}_{11} \mathrm{H}_{11} \mathrm{O}_{4} \mathrm{NBrB}(\mathrm{M})^{+}$: 310.9964

Found:

310.9967 
Elemental Analysis
Calculated:
C, 42.36
$\mathrm{H}, 3.55 \mathrm{~N}, 4.49$
Br, 25.62
Found:
C, 42.25
$\mathrm{H}, 3.50 \mathrm{~N}, 4.46$
$\mathrm{Br}, 25.30$

IR (thin film, $\mathrm{cm}^{-1}$ )

$3006,2961,1743,1582,1559,1458,1447,1384,1342,1181,1153,1040,1018,997,981,865$, 811.

Boronate ester 8b. The general procedure was followed using 3-bromophenylboronic acid (2.00 g, 9.96 mmol), N-methyliminodiacetic acid $(1.47 \mathrm{~g}, 9.96 \mathrm{mmol})$, benzene $(300 \mathrm{~mL})$ and DMSO $(30 \mathrm{~mL})$. The mixture was refluxed for $18 \mathrm{~h}$. The product was eluted with $\mathrm{Et}_{2} \mathrm{O}: \mathrm{CH}_{3} \mathrm{CN}$ 1:1. The title compound was isolated as an analytically pure, colorless, crystalline solid $(2.89 \mathrm{~g}, 93 \%)$.

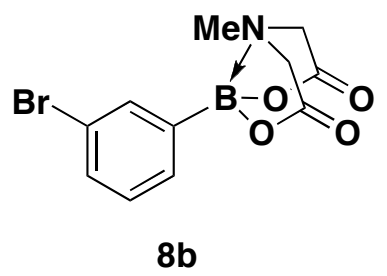

TLC (EtOAc)

$\mathrm{R}_{\mathrm{f}}=0.57$, stained by $\mathrm{KMnO}_{4}$

${ }^{1} \mathrm{H}-\mathrm{NMR}\left(500 \mathrm{MHz}, \mathrm{CD}_{3} \mathrm{CN}\right)$

ठ $7.63(\mathrm{~m}, 1 \mathrm{H}), 7.56(\mathrm{~m}, 1 \mathrm{H}), 7.46(\mathrm{~m}, 1 \mathrm{H}), 7.30(\mathrm{~m}, 1 \mathrm{H}), 4.07(\mathrm{~d}, J=17 \mathrm{~Hz}, 2 \mathrm{H}), 3.90(\mathrm{~d}, J=17$

$\mathrm{Hz}, 2 \mathrm{H}), 2.52(\mathrm{~s}, 3 \mathrm{H})$.

${ }^{13} \mathrm{C}-\mathrm{NMR}\left(125 \mathrm{MHz}, \mathrm{CD}_{3} \mathrm{CN}\right)$

$\delta 169.3,136.1,133.1,132.3,131.0,123.3,62.9,48.6$.

${ }^{11} \mathrm{~B}-\mathrm{NMR}\left(100 \mathrm{MHz}, \mathrm{CD}_{3} \mathrm{CN}\right)$

$\delta 11.5$

HRMS (EI+)

Calculated for $\mathrm{C}_{11} \mathrm{H}_{11} \mathrm{O}_{4} \mathrm{NBrB}(\mathrm{M})^{+}$: 310.9964

Found: $\quad 310.9966$

Elemental Analysis

Calculated: C, 42.36 H, $3.55 \quad$ N, 4.49

Found: $\quad \mathrm{C}, 42.83, \mathrm{H}, 3.42 \quad \mathrm{~N}, 4.51$

IR (thin film, $\mathrm{cm}^{-1}$ )

3012 , 2959, 1766, 1468, 1454, 1395, 1335, 1286, 1235, 1211, 1096, 1075, 1038, 1001, 892, 860, $787,693$.

Boronate ester 8c. The general procedure was followed using 2-bromophenylboronic acid (2.00 g, 9.96 mmol), N-methyliminodiacetic acid $(1.47 \mathrm{~g}, 9.96 \mathrm{mmol})$, benzene $(300 \mathrm{~mL})$ and DMSO (30 $\mathrm{mL})$. The mixture was refluxed for $13 \mathrm{~h}$. The product was eluted with $\mathrm{Et}_{2} \mathrm{O}: \mathrm{MeCN}$ 1:1. The title compound was isolated as an analytically pure, colorless, crystalline solid $(3.01 \mathrm{~g}, 97 \%)$. 


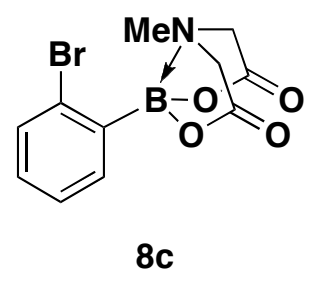

TLC (EtOAc)

$\mathrm{R}_{\mathrm{f}}=0.44$, stained by $\mathrm{KMnO}_{4}$

${ }^{1} \mathrm{H}-\mathrm{NMR}\left(500 \mathrm{MHz}, \mathrm{CD}_{3} \mathrm{CN}\right)$

$\delta 7.66(\mathrm{dd}, J=7.5,2 \mathrm{~Hz}, 1 \mathrm{H}), 7.60(\mathrm{dd}, J=8,1 \mathrm{~Hz}, 1 \mathrm{H}), 7.38(\operatorname{app~dt}, J=7.5,1 \mathrm{~Hz}, 1 \mathrm{H}), 7.29$ (app dt, $J=8,2 \mathrm{~Hz}, 1 \mathrm{H}), 4.13(\mathrm{~d}, J=17 \mathrm{~Hz}, 2 \mathrm{H}), 4.02$ (d, $J=17 \mathrm{~Hz}, 2 \mathrm{H}), 2.70$ (s, 3H).

${ }^{13} \mathrm{C}-\mathrm{NMR}\left(125 \mathrm{MHz}, \mathrm{CD}_{3} \mathrm{CN}\right)$

$\delta 169.6,137.4,134.6,132.4,128.7,128.0,65.2,49.5$.

${ }^{11} \mathrm{~B}-\mathrm{NMR}\left(100 \mathrm{MHz}, \mathrm{CD}_{3} \mathrm{CN}\right)$

$\delta 12.1$

HRMS (EI+)

Calculated for $\mathrm{C}_{11} \mathrm{H}_{11} \mathrm{O}_{4} \mathrm{NBrB}(\mathrm{M})^{+}: 310.9964$

Found:

310.9967

Elemental Analysis
Calculated:
C, 42.36
$\mathrm{H}, 3.55 \mathrm{~N}, 4.49$
$\mathrm{Br}, 25.62$
Found:
C, 42.41
$\mathrm{H}, 3.53 \mathrm{~N}, 4.50$
Br, 25.21

IR (thin film, $\mathrm{cm}^{-1}$ )

$3011,2963,1767,1709,1485,1556,1453,1418,1338,1299,1276,1198,1119,1060,1036$, $1002,879,858,759$.

Boronate ester 8d. The general procedure was followed using 4-bromothiophene-2-boronic acid (281 $\mathrm{mg}, 1.36 \mathrm{mmol})$, N-methyliminodiacetic acid (240 mg, $1.63 \mathrm{mmol})$, benzene (50 mL) and DMSO (5 mL). The mixture was refluxed for $13 \mathrm{~h}$. The product was eluted with $\mathrm{Et}_{2} \mathrm{O}: \mathrm{MeCN}$ 3:1. The title compound was isolated as an analytically pure, colorless, crystalline solid (429 mg, 99\%).

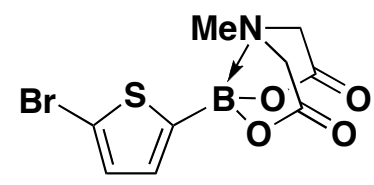

TLC $\left(\mathrm{Et}_{2} \mathrm{O}: \mathrm{MeCN} 3: 1\right)$

8d

$\mathrm{R}_{\mathrm{f}}=0.56$, stained by $\mathrm{KMnO}_{4}$

${ }^{1} \mathrm{H}-\mathrm{NMR}\left(500 \mathrm{MHz}, \mathrm{CD}_{3} \mathrm{CN}\right)$

$\delta 7.17(\mathrm{~d}, J=3.5 \mathrm{~Hz}, 1 \mathrm{H}), 7.06(\mathrm{~d}, J=3.5 \mathrm{~Hz}, 1 \mathrm{H}), 4.06(\mathrm{~d}, J=17 \mathrm{~Hz}, 2 \mathrm{H}), 3.90(\mathrm{~d}, J=17 \mathrm{~Hz}$, 2H), 2.64 (s, 3H). 
${ }^{13} \mathrm{C}-\mathrm{NMR}\left(100 \mathrm{MHz}, \mathrm{CD}_{3} \mathrm{CN}\right)$

ठ $168.9,135.1,132.8,116.2,62.5,48.4$

${ }^{11} \mathrm{~B}-\mathrm{NMR}\left(100 \mathrm{MHz}, \mathrm{CD}_{3} \mathrm{CN}\right)$

ठ 10.6

HRMS (EI+)

Calculated for $\mathrm{C}_{9} \mathrm{H}_{9} \mathrm{O}_{4} \mathrm{NBrBS}(\mathrm{M})^{+}: 316.9529$

Found:

316.9526

Elemental Analysis

Calculated: C, $34.00 \quad$ H, $2.85 \quad$ N, 4.41

Found: $\quad$ C, 34.12 H, $2.45 \quad$ N, 4.34

IR (thin film, $\mathrm{cm}^{-1}$ )

3003, 1771, 1519, 1452, 1422, 1337, 1293, 1284, 1210, 1166, 1031, 981, 966, 870, 824, 790.

Boronate ester 8e. The general procedure was followed 2-(3-bromophenyl)ethenylboronic acid (227 mg, $1.0 \mathrm{mmol})$, N-methyliminodiacetic acid (147 mg, $1.0 \mathrm{mmol})$, benzene $(50 \mathrm{~mL})$ and DMSO $(5 \mathrm{~mL})$. The mixture was refluxed for $11 \mathrm{~h}$. The product was eluted with $\mathrm{Et}_{2} \mathrm{O}: \mathrm{MeCN}$ 5:1. The title compound was isolated as an analytically pure, colorless, crystalline solid (334 mg, 99\%).

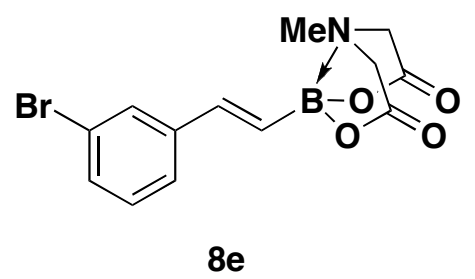

TLC (EtOAc)

$\mathrm{R}_{\mathrm{f}}=0.27$, stained by $\mathrm{KMnO}_{4}$

${ }^{1} \mathrm{H}-\mathrm{NMR}\left(500 \mathrm{MHz}, \mathrm{CD}_{3} \mathrm{CN}\right)$

ठ $7.70(\mathrm{~m}, 1 \mathrm{H}), 7.47(\mathrm{~m}, 1 \mathrm{H}), 7.42(\mathrm{~m}, 1 \mathrm{H}), 7.26(\mathrm{~m}, 1 \mathrm{H}), 6.89(\mathrm{~d}, J=18 \mathrm{~Hz}, 1 \mathrm{H}), 6.32(\mathrm{~d}, J=18$

Hz, 1H), 3.99 (d, $J=17 \mathrm{~Hz}, 2 \mathrm{H}), 3.83$ (d, $J=17 \mathrm{~Hz}, 2 \mathrm{H}), 2.80$ (s, 3H).

${ }^{13} \mathrm{C}-\mathrm{NMR}\left(125 \mathrm{MHz}, \mathrm{CD}_{3} \mathrm{CN}\right)$

ठ 169.3, 141.6, 141.5, 131.6, 131.4, 130.2, 126.6, 123.2, 62.4, 47.7.

${ }^{11} \mathrm{~B}-\mathrm{NMR}\left(100 \mathrm{MHz}, \mathrm{CD}_{3} \mathrm{CN}\right)$

ठ 11.3

HRMS (EI+)

Calculated for $\mathrm{C}_{13} \mathrm{H}_{13} \mathrm{O}_{4} \mathrm{NBrB}(\mathrm{M})^{+}: 337.0121$

Found:

337.0123

Elemental Analysis

Calculated: C, 46.20 H, $3.88 \quad \mathrm{~N}, 4.14$

Found: $\quad$ C, 46.22 H, $3.51 \quad \mathrm{~N}, 4.12$ 
IR (thin film, $\mathrm{cm}^{-1}$ )

$3010,2958,1759,1627,1588,1560,1469,1424,1337,1291,1233,1198,1154,1114,1088$,

1071, 1029, 994, 956, 875, 826, 778, 729, 679, 661, 593.

Boronate ester 8f. The general procedure was followed using 2-(3-bromophenyl)cyclopropylboronic acid (19, see below for the preparation of this material) $(316 \mathrm{mg}, 1.31 \mathrm{mmol}), \mathrm{N}$-methyliminodiacetic acid (232 $\mathrm{mg}, 1.58 \mathrm{mmol})$, benzene $(50 \mathrm{~mL})$ and DMSO $(5 \mathrm{~mL})$. The mixture was refluxed for $6 \mathrm{~h}$. The product was eluted with $\mathrm{MeCN}: \mathrm{Et}_{2} \mathrm{O}$ 5:1. The title compound was isolated as an analytically pure, colorless solid (408 $\mathrm{mg}, 88 \%$ ).

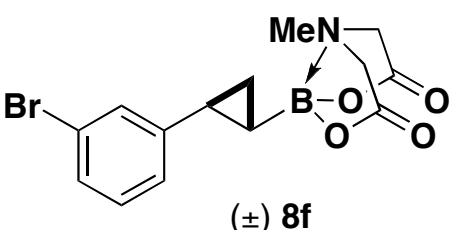

TLC (EtOAc)

$\mathrm{R}_{\mathrm{f}}=0.27$, stained by $\mathrm{KMnO}_{4}$

${ }^{1} \mathrm{H}-\mathrm{NMR}\left(500 \mathrm{MHz}, \mathrm{CD}_{3} \mathrm{CN}\right)$

d 7.28-7.26 (m, 2H), $7.15(\mathrm{~m}, 1 \mathrm{H}), 7.09(\mathrm{~m}, 1 \mathrm{H}), 3.96(\operatorname{app} \mathrm{dd}, J=17,3 \mathrm{~Hz}, 2 \mathrm{H}), 3.84(\operatorname{app} \mathrm{dd}, J$ $=17,9.5 \mathrm{~Hz}, 2 \mathrm{H}), 1.77(\mathrm{ddd}, J=8,5.5,5 \mathrm{~Hz}, 1 \mathrm{H}), 0.96-0.87(\mathrm{~m}, 2 \mathrm{H}), 0.19$ (ddd, $J=10,7,5.5$ $\mathrm{Hz}, 1 \mathrm{H})$.

${ }^{13} \mathrm{C}-\mathrm{NMR}\left(125 \mathrm{MHz}, \mathrm{CD}_{3} \mathrm{CN}\right)$

ठ $169.3,169.1,148.3,131.1,129.1,129.1,125.4,123.0,63.1,63.0,47.4,19.6,13.8$.

${ }^{11} \mathrm{~B}-\mathrm{NMR}\left(100 \mathrm{MHz}, \mathrm{CD}_{3} \mathrm{CN}\right)$

$\delta 12.6$

HRMS (EI+)

Calculated for $\mathrm{C}_{14} \mathrm{H}_{15} \mathrm{O}_{4} \mathrm{NBrB}(\mathrm{M})^{+}$: 351.0277

Found:

351.0274

Elemental Analysis

Calculated: C, $47.77 \quad \mathrm{H}, 4.30 \quad$ N, 3.98

Found: $\quad$ C, 47.89 H, $4.35 \quad$ N, 3.95

IR (thin film, $\mathrm{cm}^{-1}$ )

3004, 2968, 2922, 1749, 1716, 1422, 1363, 1222, 1092, 900, 736. 


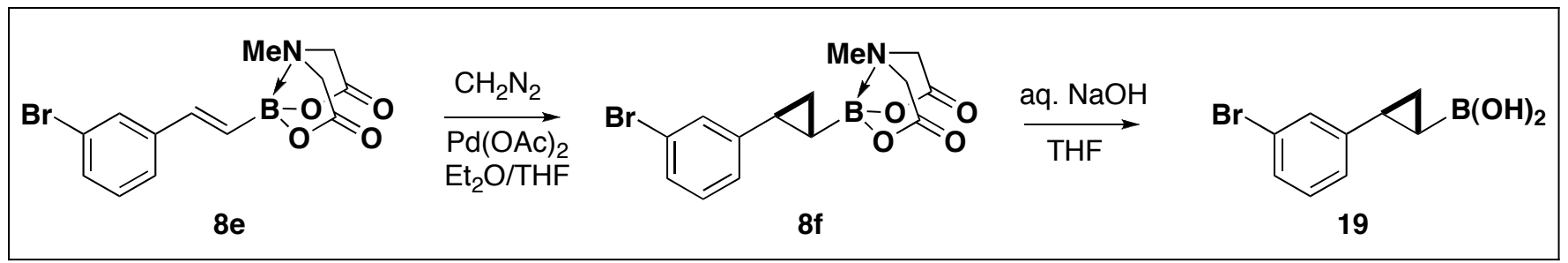

2-(3-bromophenyl)cyclopropylboronic acid (19). To a stirred solution of 8 e (1.21 g, $3.59 \mathrm{mmol})$ and $\mathrm{Pd}(\mathrm{OAc})_{2}(0.0239 \mathrm{~g}, 0.11 \mathrm{mmol})$ in THF $(24 \mathrm{~mL})$ at $0{ }^{\circ} \mathrm{C}$ in a $250 \mathrm{~mL}$ Schlenk flask was added a freshly prepared ethereal solution of diazomethane $(35 \mathrm{~mL}$ of a $0.25 \mathrm{M}$ solution, $8.8 \mathrm{mmol}$ ) dropwise over 20 minutes. Additional $\mathrm{Pd}(\mathrm{OAc})_{2}$ was then added $(0.0239 \mathrm{~g}, 0.11 \mathrm{mmol})$ as a solution in $\mathrm{THF}(1 \mathrm{~mL})$ followed by the dropwise addition over $20 \mathrm{~min}$ of an additional $35 \mathrm{~mL}$ of $0.25 \mathrm{M}$ ethereal diazomethane $(8.8 \mathrm{mmol})$. The reaction was then allowed to warm to $23{ }^{\circ} \mathrm{C}$ and the excess diazomethane was removed under a stream of $\mathrm{N}_{2}$. The crude reaction mixture was then poured into $120 \mathrm{~mL}$ of $0.5 \mathrm{M} \mathrm{pH} 7$ sodium phosphate buffer and extracted with THF: $\mathrm{Et}_{2} \mathrm{O}$ 1:1 (3 x $\left.120 \mathrm{~mL}\right)$. The combined organic fractions were then washed with brine, dried over $\mathrm{Na}_{2} \mathrm{SO}_{4}$, and concentrated in vacuo. Purification by flash chromatography $\left(\mathrm{SiO}_{2}, \mathrm{Et}_{2} \mathrm{O} \rightarrow \mathrm{Et}_{2} \mathrm{O}: \mathrm{CH}_{3} \mathrm{CN}\right.$ 1:1) yielded 8f (1.21 g, 96\%) (See above for characterization of $\mathbf{8 f}$.) To a stirred solution of $\mathbf{8 f}(0.513 \mathrm{~g}, 1.46 \mathrm{mmol})$ in THF $(20 \mathrm{~mL})$ was added $1 \mathrm{M}$ aq. $\mathrm{NaOH}(4.37 \mathrm{~mL}, 4.37 \mathrm{mmol})$ and the resulting mixture was stirred at $23{ }^{\circ} \mathrm{C}$ for 20 minutes. The reaction was then quenched with the addition of $0.5 \mathrm{M} \mathrm{pH} 7$ phosphate buffer $(20 \mathrm{~mL})$ and diluted with $\mathrm{Et}_{2} \mathrm{O}(20 \mathrm{~mL})$. The layers were separated and the aq. layer was extracted with THF: $\mathrm{Et}_{2} \mathrm{O} 1: 1(40 \mathrm{~mL})$. The combined organic fractions were dried over $\mathrm{MgSO}_{4}$ and concentrated in vacuo to yield the desired cyclopropylboronic acid 19 as a colorless solid $(0.339 \mathrm{~g}, 97 \%)$.

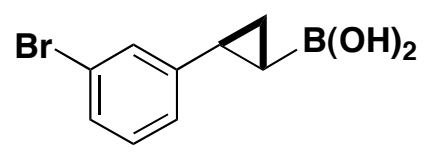

TLC $\left(\mathrm{Et}_{2} \mathrm{O}: \mathrm{CH}_{3} \mathrm{CN} 3: 1\right)$

19

$\mathrm{R}_{\mathrm{f}}=0.64$, visualized by $\mathrm{UV}$

${ }^{1} \mathrm{H}-\mathrm{NMR}\left(500 \mathrm{MHz}, d_{6}\right.$-DMSO:D $\left.2 \mathrm{O} 95: 5\right)$

$\delta 7.30(\mathrm{~d}, J=8 \mathrm{~Hz}, 1 \mathrm{H}), 7.23(\mathrm{~s}, 1 \mathrm{H}), 7.19(\operatorname{app~t}, J=8 \mathrm{~Hz}, 1 \mathrm{H}), 7.07$ (d, $J=8 \mathrm{~Hz}, 1 \mathrm{H}), 1.95$ (m, $1 \mathrm{H}), 1.06(\mathrm{~m}, 1 \mathrm{H}), 0.96(\mathrm{~m}, 1 \mathrm{H}), 0.07(\mathrm{~m}, 1 \mathrm{H})$.

${ }^{13} \mathrm{C}-\mathrm{NMR}\left(125 \mathrm{MHz}, \mathrm{CD}_{3} \mathrm{CN}\right)$

ठ $147.2,130.3,127.9,127.7,124.3,121.7,20.8,14.8$.

HRMS (EI+)

Calculated for $\mathrm{C}_{9} \mathrm{H}_{10} \mathrm{O}_{2} \mathrm{BrB}(\mathrm{M})^{+}: \quad 239.9957$

Found:

239.9956 


\section{Selective Suzuki-Miyaura coupling with haloboronate esters (Table 2)}

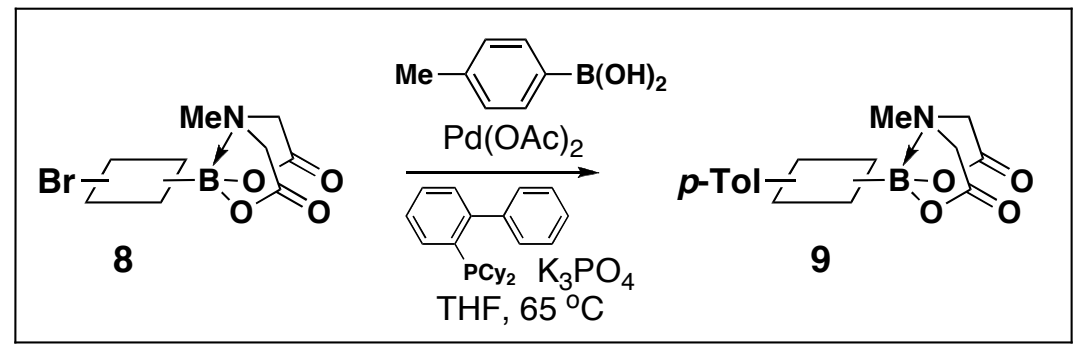

\section{General procedures for selective Suzuki-Miyaura coupling reactions.}

It was determined that the same yield was observed for the transformation of $8 \boldsymbol{a} \rightarrow \mathbf{9 a}$ whether this reaction was set up in the glovebox or in the air (see below).

Preparation of catalyst stock. In a glove box, to a vial equipped with a stir bar was added the phosphine ligand. To the vial was then added a $0.02 \mathrm{M}$ solution of $\mathrm{Pd}(\mathrm{OAc})_{2}$ in THF in a volume sufficient to yield a $0.04 \mathrm{M}$ solution with respect to the phosphine ligand. The vial was sealed with a PTFE-lined cap, removed from the glove box, and maintained at $65^{\circ} \mathrm{C}$ with stirring for $30 \mathrm{~min}$.

Suzuki-Miyaura Coupling. To a $40 \mathrm{~mL}$ vial equipped with a stir bar was added the haloboronate ester (1.0 mmol) and the boronic acid (typically $1.2-1.5 \mathrm{mmol})$. The vial was brought into the glove box. To the vial was added $\mathrm{K}_{3} \mathrm{PO}_{4}(3.0 \mathrm{mmol}, 636.8 \mathrm{mg}$, a finely ground powder), THF $(9.0 \mathrm{~mL})$, and then the catalyst stock solution $(1.0 \mathrm{~mL})$. The vial was capped with a PTFE-lined cap, removed from the glove box, and placed in a $65^{\circ} \mathrm{C}$ oil bath with stirring for $12 \mathrm{~h}$. The reaction mixture was allowed to cool to 23 ${ }^{\circ} \mathrm{C}$ and then filtered through a very thin pad of silica gel topped with sand and then celite, eluting with a copious volume of MeCN. To the resulting solution was added Florisil gel (app. $25 \mathrm{mg} / \mathrm{mL}$ of solution), and then solvent was removed in vacuo. The resulting powder was dry-loaded on top of a silica gel column slurry-packed with $\mathrm{Et}_{2} \mathrm{O}$. The column was flushed with a copious volume of $\mathrm{Et}_{2} \mathrm{O}$; the product was then eluted with $\mathrm{Et}_{2} \mathrm{O}: \mathrm{MeCN}$.

Boronate ester 9a. The general procedure was followed using 8a (312 $\mathrm{mg}, 1.00 \mathrm{mmol}$ ), tolylboronic acid (163 mg, $1.20 \mathrm{mmol}$ ), and 2-(dicyclohexylphosphino)biphenyl. The product was eluted with $\mathrm{Et}_{2} \mathrm{O}: \mathrm{MeCN}$ 1:1. The title compound was isolated as a colorless solid (280 mg, 87\%).

This same reaction was also set up using standard Schlenk techniques without the use of a glove box. A flame-dried $25 \mathrm{~mL}$ Schlenk flask equipped with a stir bar was evacuated and purged with argon 3 times. This flask was charged with 2-(dicyclohexylphosphino)biphenyl (14.1 mg, $0.04 \mathrm{mmol}) \mathrm{Pd}(\mathrm{OAc})_{2}(4.4 \mathrm{mg}$, $0.02 \mathrm{mmol})$, and THF $(10 \mathrm{~mL})$. The flask was then fitted with a reflux condensor and the yellow solution was heated to reflux for 5 minutes resulting in discoloration. A separate flame-dried $25 \mathrm{~mL}$ Schlenk flask equipped with a stir bar was evacuated and purged with argon 3 times. This flask was charged with haloboronate ester 8a $(312.1 \mathrm{mg}, 1.00 \mathrm{mmol})$, tolylboronic acid (163.2 $\mathrm{mg}, 1.20 \mathrm{mmol})$, and freshly ground anhydrous $\mathrm{K}_{3} \mathrm{PO}_{4}(637.2 \mathrm{mg}, 3.00 \mathrm{mmol})$. This flask was then fitted with a reflux condensor. The catalyst solution was then transferred via cannula into the flask containing the coupling partners and base. The resulting mixture was heated at reflux for 12 hours. The reaction was worked-up as described in the general procedure above. The product was eluted with $\mathrm{Et}_{2} \mathrm{O}: \mathrm{MeCN} 3: 1 \rightarrow$ 1:1. The title compound was isolated as a nearly colorless solid $(279.6 \mathrm{mg}, 87 \%)$. 


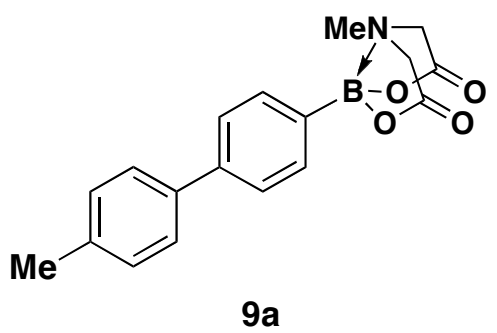

TLC (EtOAc)

$\mathrm{R}_{\mathrm{f}}=0.29$, stained by $\mathrm{KMnO}_{4}$

${ }^{1} \mathrm{H}-\mathrm{NMR}\left(500 \mathrm{MHz}, \mathrm{CD}_{3} \mathrm{CN}\right)$

$\delta 7.64(\mathrm{~d}, J=8 \mathrm{~Hz}, 2 \mathrm{H}), 7.55(\operatorname{app~d}, J=7.5 \mathrm{~Hz}, 4 \mathrm{H}), 7.27(\mathrm{~d}, J=8 \mathrm{~Hz}, 2 \mathrm{H}), 4.07(\mathrm{~d}, J=17 \mathrm{~Hz}$, $2 \mathrm{H}), 3.90(\mathrm{~d}, J=17 \mathrm{~Hz}, 2 \mathrm{H}), 2.54(\mathrm{~s}, 3 \mathrm{H}), 2.37(\mathrm{~s}, 3 \mathrm{H})$.

${ }^{13} \mathrm{C}-\mathrm{NMR}\left(125 \mathrm{MHz}, \mathrm{CD}_{3} \mathrm{CN}\right)$

ठ $169.6,142.5,138.6,138.4,134.0,130.5,127.7,127.1,62.8,48.5,21.1$.

${ }^{11} \mathrm{~B}-\mathrm{NMR}\left(100 \mathrm{MHz}, \mathrm{CD}_{3} \mathrm{CN}\right)$

$\delta 12.0$

HRMS (EI+)

Calculated for $\mathrm{C}_{18} \mathrm{H}_{18} \mathrm{O}_{4} \mathrm{NB}(\mathrm{M})^{+}$: $\quad 323.1329$

Found:

323.1332

IR (thin film, $\mathrm{cm}^{-1}$ )

3012 , 2952, 1765, 1711, 1607, 1455, 1340, 1297, 1237, 1202, 1040, 992, 891, 866, 840, 806.

Boronate ester 9b. The general procedure was followed using $\mathbf{8 b}$ (312 $\mathrm{mg}, 1.00 \mathrm{mmol}$ ), tolylboronic acid (163 mg, $1.20 \mathrm{mmol}$ ), and 2-(dicyclohexylphosphino)biphenyl. The product was eluted with $\mathrm{Et}_{2} \mathrm{O}: \mathrm{MeCN} 1: 1$. The title compound was isolated as a colorless, crystalline solid (276 mg, 85\%).

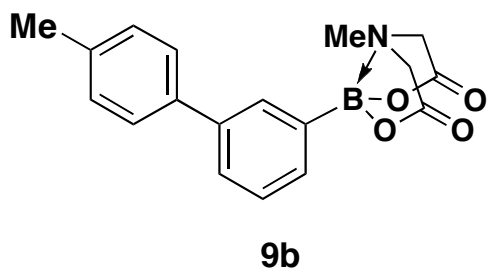

TLC (EtOAc)

$\mathrm{R}_{\mathrm{f}}=0.38$, stained by $\mathrm{KMnO}_{4}$

${ }^{1} \mathrm{H}-\mathrm{NMR}\left(500 \mathrm{MHZ}, \mathrm{CD}_{3} \mathrm{CN}\right)$

d $7.12(\mathrm{~m}, 1 \mathrm{H}), 7.64(\mathrm{~m}, 1 \mathrm{H}), 7.55(\mathrm{~m}, 2 \mathrm{H}), 7.45(\mathrm{~m}, 2 \mathrm{H}), 7.27(\operatorname{app~d}, J=8 \mathrm{~Hz}, 2 \mathrm{H}), 4.07(\mathrm{~d}, J=$

$17 \mathrm{~Hz}, 2 \mathrm{H}), 3.91(\mathrm{~d}, J=17 \mathrm{~Hz}, 2 \mathrm{H}), 2.53(\mathrm{~s}, 3 \mathrm{H}), 2.36(\mathrm{~s}, 3 \mathrm{H})$.

${ }^{13} \mathrm{C}-\mathrm{NMR}\left(100 \mathrm{MHz}, \mathrm{CD}_{3} \mathrm{CN}\right)$

ठ $169.6,141.2,139.2,138.2,132.3,131.7,130.5,129.4,128.7,127.8,62.9,48.6,21.1$.

${ }^{11} \mathrm{~B}-\mathrm{NMR}\left(100 \mathrm{MHZ}, \mathrm{CD}_{3} \mathrm{CN}\right)$

$\delta 12.2$ 
HRMS (EI+)

Calculated for $\mathrm{C}_{18} \mathrm{H}_{18} \mathrm{O}_{4} \mathrm{NB}(\mathrm{M})^{+}: \quad 323.1329$

Found:

IR (thin film, $\mathrm{cm}^{-1}$ )

$3050,3017,2959,2920,1765,1515,1456,1420,1389,1336,1295,1238,1220,1203,1097$, $1058,1035,965,891,861,794,730,710,652$.

Boronate ester 9c. The general procedure was followed using 8c (312 mg, $1.00 \mathrm{mmol})$, tolylboronic acid $(172 \mathrm{mg}, 2.00 \mathrm{mmol})$ and 2-(dicyclohexylphosphino)biphenyl. The product was eluted with a gradient of $\mathrm{Et}_{2} \mathrm{O}: \mathrm{MeCN} 5: 1 \rightarrow$ 1:1. The title compound was isolated as a pale yellow solid $(257 \mathrm{mg}, 80 \%)$.

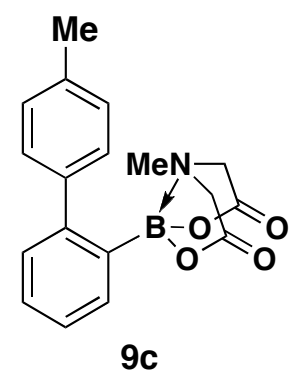

TLC (EtOAc)

$\mathrm{R}_{\mathrm{f}}=0.40$, stained by $\mathrm{KMnO}_{4}$

${ }^{1} \mathrm{H}-\mathrm{NMR}\left(500 \mathrm{MHz}, \mathrm{CD}_{3} \mathrm{CN}\right)$

ठ $7.72(\mathrm{dd}, J=7.25,1 \mathrm{~Hz}, 1 \mathrm{H}), 7.43-7.34(\mathrm{~m}, 2 \mathrm{H}), 7.18-7.08(\mathrm{~m}, 5 \mathrm{H}), 3.73(\mathrm{~d}, J=17 \mathrm{~Hz}, 2 \mathrm{H})$,

$3.27(\mathrm{~d}, J=17 \mathrm{~Hz}, 2 \mathrm{H}), 2.42(\mathrm{~s}, 3 \mathrm{H}), 2.34(\mathrm{~s}, 3 \mathrm{H})$.

${ }^{13} \mathrm{C}-\mathrm{NMR}\left(125 \mathrm{MHz}, \mathrm{CD}_{3} \mathrm{CN}\right)$

ठ 168.9, 148.8, 141.8, 137.4, 135.2, 132.0, 130.5, 129.9, 129.4, 127.6, 63.5, 48.5, 21.1.

${ }^{11} \mathrm{~B}-\mathrm{NMR}\left(100 \mathrm{MHz}, \mathrm{CD}_{3} \mathrm{CN}\right)$

$\delta 12.5$

HRMS (EI+):

Calculated for $\mathrm{C}_{18} \mathrm{H}_{18} \mathrm{O}_{4} \mathrm{NB}(\mathrm{M})^{+}$: $\quad 323.1329$

Found:

323.1332

IR (thin film, $\mathrm{cm}^{-1}$ )

$3051,3013,2956,2923,2869,1770,1592,1515,1452,1431,1336,1299,1279,1197,1112$, $1030,1005,887,857,824,770,755,706,639$.

Boronate ester 9d. The general procedure was followed using 8d (318 $\mathrm{mg}, 1.00 \mathrm{mmol}$ ), tolylboronic acid (204 mg, $1.50 \mathrm{mmol}$ ), $\mathrm{K}_{2} \mathrm{CO}_{3}$ (415 mg, $3.00 \mathrm{mmol}$,) and 2-(dicyclohexylphosphino)-2',4',6'-triisopropyl-1,1'-biphenyl. The product was eluted using a gradient of $\mathrm{Et}_{2} \mathrm{O}: \mathrm{MeCN}$ 5:1 $\rightarrow$ 3:1. The title compound was isolated as a pale yellow solid (266 $\mathrm{mg}, 81 \%)$. 


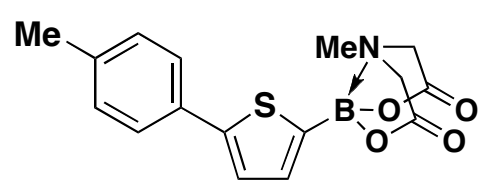

9d

TLC (EtOAc)

$\mathrm{R}_{\mathrm{f}}=0.52$, stained by $\mathrm{KMnO}_{4}$

${ }^{1} \mathrm{H}-\mathrm{NMR}\left(400 \mathrm{MHz}, \mathrm{CD}_{3} \mathrm{CN}\right)$

$\delta 7.56(\mathrm{~d}, J=8 \mathrm{~Hz}, 2 \mathrm{H}), 7.41(\mathrm{~d}, J=3.2 \mathrm{~Hz}, 1 \mathrm{H}), 7.23(\mathrm{~d}, J=3.2 \mathrm{~Hz}, 1 \mathrm{H}), 7.21(\mathrm{~d}, J=8 \mathrm{~Hz}, 2 \mathrm{H})$, $4.08(\mathrm{~d}, J=17 \mathrm{~Hz}, 2 \mathrm{H}), 3.92$ (d, $J=17 \mathrm{~Hz}, 2 \mathrm{H}), 2.66$ (s, 3H), 2.33 (s, 3H).

${ }^{13} \mathrm{C}-\mathrm{NMR}\left(125 \mathrm{MHz}, \mathrm{CD}_{3} \mathrm{CN}\right)$

$\delta$ 169.0, 149.4, 138.8, 135.4, 132.4, 130.6, 126.6, 125.2, 62.4, 48.4, 21.1.

${ }^{11} \mathrm{~B}-\mathrm{NMR}\left(100 \mathrm{MHz}, \mathrm{CD}_{3} \mathrm{CN}\right)$

$\delta 11.2$

HRMS (TOF ES+)

Calculated for $\mathrm{C}_{16} \mathrm{H}_{16} \mathrm{O}_{4} \mathrm{BNNaS}(\mathrm{M}+\mathrm{Na})^{+}: \quad 352.0791$

Found:

352.0800

IR (thin film, $\mathrm{cm}^{-1}$ )

2999, 2948, 1755, 1453, 1337, 1284, 1248, 1169, 1031, 978, 894, 869, 802.

Boronate ester 9e. The general procedure was followed using $8 \mathbf{e}(338 \mathrm{mg}, 1.00 \mathrm{mmol})$, tolylboronic acid $(163 \mathrm{mg}, 1.20 \mathrm{mmol})$, and 2-(dicyclohexylphosphino)biphenyl. The product was eluted with $\mathrm{Et}_{2} \mathrm{O}: \mathrm{MeCN}$ 5:1. The title compound was isolated as an off-white solid $(282 \mathrm{mg}, 82 \%)$.

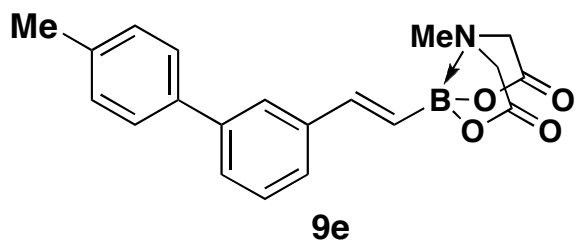

TLC (EtOAc)

$\mathrm{R}_{\mathrm{f}}=0.29$, stained by $\mathrm{KMnO}_{4}$

${ }^{1} \mathrm{H}-\mathrm{NMR}\left(500 \mathrm{MHz}, \mathrm{CD}_{3} \mathrm{CN}\right)$

$\delta 7.76($ app t $, J=1.5 \mathrm{~Hz}, 1 \mathrm{H}), 7.55(\mathrm{~m}, 2 \mathrm{H}), 7.50(\mathrm{~m}, 2 \mathrm{H}), 7.40($ app t, $J=8 \mathrm{~Hz}, 1 \mathrm{H}), 7.27$ (app d, $J=8 \mathrm{~Hz}, 2 \mathrm{H}), 7.01(\mathrm{~d}, J=18.5 \mathrm{~Hz}, 1 \mathrm{H}), 6.37(\mathrm{~d}, J=18.5 \mathrm{~Hz}, 1 \mathrm{H}), 4.00(\mathrm{~d}, J=17 \mathrm{~Hz}, 2 \mathrm{H}), 3.84$ $(\mathrm{d}, J=17 \mathrm{~Hz}, 2 \mathrm{H}), 2.81(\mathrm{~s}, 3 \mathrm{H}), 2.36(\mathrm{~s}, 3 \mathrm{H})$.

${ }^{13} \mathrm{C}-\mathrm{NMR}\left(125 \mathrm{MHz}, \mathrm{CD}_{3} \mathrm{CN}\right)$

$\delta 169.5,143.3,142.2,139.8,138.8,138.5,130.6,130.1,127.9,127.5,126.4,126.2,62.5,47.8$, 21.2.

${ }^{11} \mathrm{~B}-\mathrm{NMR}\left(100 \mathrm{MHz}, \mathrm{CD}_{3} \mathrm{CN}\right)$

$\delta 11.9$ 
HRMS (EI+)

Calculated for $\mathrm{C}_{20} \mathrm{H}_{20} \mathrm{O}_{4} \mathrm{NB}(\mathrm{M})^{+}: \quad 349.1485$

Found:

IR (thin film, $\mathrm{cm}^{-1}$ )

$3005,2952,2922,2868,1764,1628,1598,1582,1517,1427,1396,1337,1289,1233,1192$,

$1153,1114,1086,1028,995,956,878,823,785,697$.

Boronate ester 9f. The general procedure was followed using $8 \mathbf{f}$ ( $237 \mathrm{mg}, 0.674 \mathrm{mmol}$ ), tolylboronic acid (109 mg, $0.808 \mathrm{mmol}), \mathrm{K}_{3} \mathrm{PO}_{4}(429 \mathrm{mg}, 2.02 \mathrm{mmol})$, catalyst stock solution containing 2(dicyclohexylphosphino)biphenyl $(674 \mu \mathrm{L})$, and THF $6.06 \mathrm{~mL}$. The product was eluted with $\mathrm{Et}_{2} \mathrm{O}: \mathrm{MeCN}$ (1:1). The title compound was isolated as an off-white crystalline solid (229 $\mathrm{mg}, 94 \%)$.

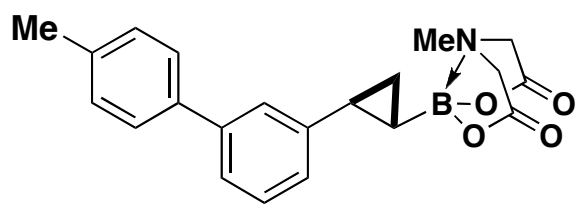

$( \pm) 9 f$

TLC (EtOAc)

$\mathrm{R}_{\mathrm{f}}=0.33$, stained by $\mathrm{KMnO}_{4}$

${ }^{1} \mathrm{H}-\mathrm{NMR}\left(500 \mathrm{MHz}, \mathrm{CD}_{3} \mathrm{CN}\right)$

$\delta 7.51(\operatorname{app~d}, J=8 \mathrm{~Hz}, 2 \mathrm{H}), 7.35(\mathrm{~m}, 2 \mathrm{H}), 7.29$ (app t, $J=8 \mathrm{~Hz}, 1 \mathrm{H}), 7.07$ (app d, $J=8 \mathrm{~Hz}, 1 \mathrm{H})$, 3.96 (app dd, $J=17,4 \mathrm{~Hz}, 2 \mathrm{H}), 3.84$ (app dd, $J=17,12 \mathrm{~Hz}, 2 \mathrm{H}), 1.84$ (ddd, $J=8,5.5,5 \mathrm{~Hz}, 1 \mathrm{H}$ ), 0.99 (ddd, $J=10,5,4 \mathrm{~Hz}, 1 \mathrm{H}), 0.91$ (ddd, $J=8,7,4 \mathrm{~Hz}, 1 \mathrm{H}), 0.25$ (ddd, $J=10,7,5.5 \mathrm{~Hz}, 1 \mathrm{H}$ ).

${ }^{13} \mathrm{C}-\mathrm{NMR}\left(125 \mathrm{MHz}, \mathrm{CD}_{3} \mathrm{CN}\right)$

ठ 168.0, 167.9, 144.6, 140.5, 137.8, 136.9, 129.1, 128.5, 126.5, 123.7, 123.5, 123.4, 61.8, 61.7, $46.1,19.8,18.7,12.2$.

${ }^{11} \mathrm{~B}-\mathrm{NMR}\left(100 \mathrm{MHz}, \mathrm{CD}_{3} \mathrm{CN}\right)$

$\delta 13.1$

HRMS (EI+)

Calculated for $\mathrm{C}_{21} \mathrm{H}_{22} \mathrm{O}_{4} \mathrm{NB}(\mathrm{M})^{+}$: $\quad 363.1642$

Found:

363.1645

IR (thin film, $\mathrm{cm}^{-1}$ )

$3014,2963,2921,1762,1603,1517,1485,1458,1379,1338,1292,1246,1153,1115,1084$, 1030, 960, 891, 861, 825, 792, 707. 
VI. Deprotection of boronate esters (Table 2).

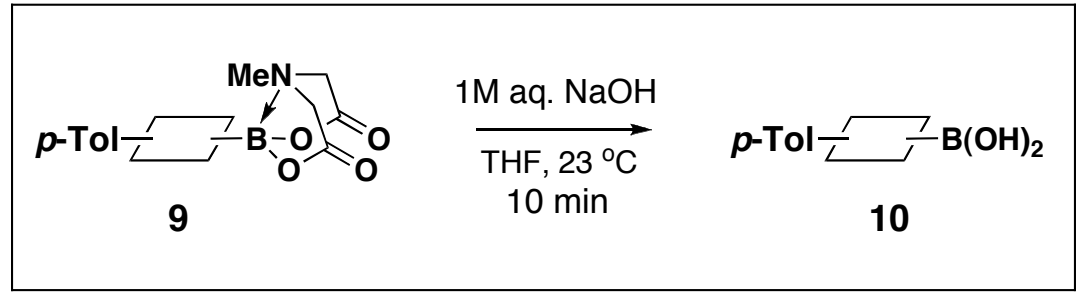

General procedure for $\mathrm{NaOH}$-mediated hydrolysis of boronate esters. A round bottom flask equipped with a stir bar was charged with the boronate ester (1 equiv.), THF $(10 \mathrm{~mL})$, and $1 \mathrm{M}$ aq. $\mathrm{NaOH}$ ( 3 equiv.) and the resulting mixture was vigorously stirred at $23{ }^{\circ} \mathrm{C}$ for 10 minutes. The reaction mixture was then diluted with aq. sodium phosphate buffer $(0.5 \mathrm{M}, \mathrm{pH} 7.0,10 \mathrm{~mL})$ and $\mathrm{Et}_{2} \mathrm{O}(10 \mathrm{~mL})$, the layers were separated, and the aq. phase was extracted once with THF:Et $\mathrm{O}_{2} 1: 1(20 \mathrm{~mL})$. (On some occasions phosphate salts precipated and during the extraction process and were redissolved by the addition of water. The combined organic fractions were then dried over $\mathrm{MgSO}_{4}$ and concentrated in vacuo. Residual solvent was co-evaporated with $\mathrm{MeCN}$.

Boronic acid 10a. The general procedure was followed using 9a (261 $\mathrm{mg}, 0.806 \mathrm{mmol})$ and $1 \mathrm{M}$ aq. $\mathrm{NaOH}(2.42 \mathrm{~mL}, 2.42 \mathrm{mmol})$. The title compound was isolated as a white solid (147.4 mg, 86\%)<smiles>Cc1ccc(-c2ccc(O)cc2)cc1</smiles>

TLC (EtOAc)

$\mathrm{R}_{\mathrm{f}}=0.55$, stained by $\mathrm{KMnO}_{4}$

${ }^{1} \mathrm{H}-\mathrm{NMR}\left(500 \mathrm{MHz}, d_{6}\right.$-DMSO: $\mathrm{D}_{2} \mathrm{O}$ 95:5)

$\delta 7.87(\mathrm{~d}, J=8 \mathrm{~Hz}, 2 \mathrm{H}), 7.62(\mathrm{~d}, J=8 \mathrm{~Hz}, 2 \mathrm{H}), 7.59(\mathrm{~d}, J=8 \mathrm{~Hz}, 2 \mathrm{H}), 7.28(\mathrm{~d}, J=8 \mathrm{~Hz}, 2 \mathrm{H})$, $2.35(\mathrm{~s}, 3 \mathrm{H})$.

${ }^{13} \mathrm{C}-\mathrm{NMR}\left(125 \mathrm{MHz}, d_{6}\right.$-DMSO: $\left.\mathrm{D}_{2} \mathrm{O} 95: 5\right)$

$\delta 141.5,137.1,136.9,134.7,129.5,126.4,125.3,20.6$.

HRMS (EI+)

Calculated for $\mathrm{C}_{13} \mathrm{H}_{13} \mathrm{O}_{2} \mathrm{~B}(\mathrm{M})^{+}$: $\quad 212.1009$

Found:

212.1011 
Boronic acid 10b. The general procedure was followed using $9 \mathrm{~b}$ (268 $\mathrm{mg}, 0.830 \mathrm{mmol})$ and $1 \mathrm{M}$ aq. $\mathrm{NaOH}$ (2.49 mL, $2.49 \mathrm{mmol})$. The title compound was isolated as a white solid (161 mg, 92\%).

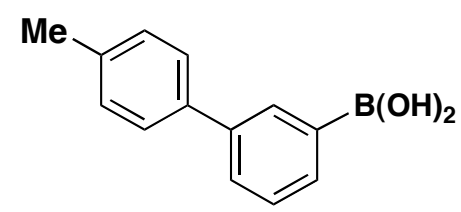

TLC (EtOAc)

$\mathrm{R}_{\mathrm{f}}=0.59$, stained by $\mathrm{KMnO}_{4}$

${ }^{1} \mathrm{H}-\mathrm{NMR}\left(500 \mathrm{MHz}, d_{6}\right.$-DMSO:D $\mathrm{O}$ 95:5)

$\delta 8.09(\mathrm{~s}, 1 \mathrm{H}), 7.75(\mathrm{~d}, J=7 \mathrm{~Hz}, 1 \mathrm{H}), 7.68(\mathrm{~d}, J=8 \mathrm{~Hz}, 2 \mathrm{H}), 7.57(\mathrm{~d}, J=8 \mathrm{~Hz}, 2 \mathrm{H}), 7.43(\operatorname{app~t}, J$ $=7.5 \mathrm{~Hz}, 1 \mathrm{H}), 7.29(\mathrm{~d}, J=8 \mathrm{~Hz}, 2 \mathrm{H}), 2.35(\mathrm{~s}, 3 \mathrm{H})$.

${ }^{13} \mathrm{C}-\mathrm{NMR}\left(125 \mathrm{MHz}, d_{6}\right.$-DMSO:D $\mathrm{O}$ 95:5)

$\delta 139.0,137.5,136.5,132.8,132.1,129.4,128.1,128.0,126.4,20.6$.

HRMS (EI+)

Calculated for $\mathrm{C}_{13} \mathrm{H}_{13} \mathrm{O}_{2} \mathrm{~B}(\mathrm{M})^{+}$: $\quad 212.1009$

Found:

\section{Boronic acid 10c.}

Hydrolysis with $\mathrm{NaOH}$. The general procedure was followed using 9c (236 mg, $0.729 \mathrm{mmol})$ and $1 \mathrm{M}$ aq. $\mathrm{NaOH}$ (2.19 mL, $2.19 \mathrm{mmol})$. The title compound was isolated as a white solid (150 mg, 97\%).

Hydrolysis with $\mathrm{NaHCO}_{3}$. To a $40 \mathrm{~mL}$ I-Chem vial equipped with a stir bar and containing 8c $(0.672$ mmol, $217 \mathrm{mg}$ ) was added $\mathrm{MeOH}(7 \mathrm{~mL})$ and sat. aq. $\mathrm{NaHCO}_{3}(3.5 \mathrm{~mL})$. The mixture was vigorously stirred for $6 \mathrm{~h}$ at $23{ }^{\circ} \mathrm{C}$. The mixture was then diluted with saturated aq. $\mathrm{NH}_{4} \mathrm{Cl}(7 \mathrm{~mL})$ and $\mathrm{Et}_{2} \mathrm{O}(14 \mathrm{~mL})$, and the phases were separated. The aqueous phase was twice extracted with $\mathrm{Et}_{2} \mathrm{O}(14 \mathrm{~mL})$, and the combined organics were dried over $\mathrm{MgSO}_{4}$ and concentrated in vacuo. The residue was twice suspended in $\mathrm{MeCN}$ followed by concentration in vacuo and then dissolved in $\mathrm{CH}_{2} \mathrm{Cl}_{2}$ and concentrated in vacuo to yield 10c as a colorless, crystalline solid (121 mg, 85\%).

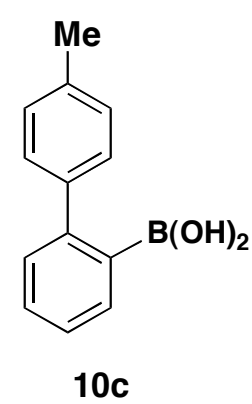

TLC (EtOAc)

$\mathrm{R}_{\mathrm{f}}=0.84$, stained by $\mathrm{KMnO}_{4}$

${ }^{1} \mathrm{H}-\mathrm{NMR}$ (500 MHz, $d_{6}$-DMSO: $\mathrm{D}_{2} \mathrm{O}$ 95:5)

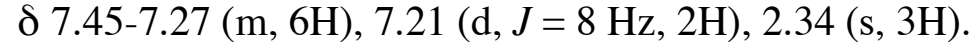


${ }^{13} \mathrm{C}-\mathrm{NMR}\left(125 \mathrm{MHz}, d_{6}\right.$-DMSO:D $\mathrm{O}$ 95:5)

ठ 144.0, 140.2, 135.8, 132.1, 128.7, 128.2, 128.0, 127.9, 125.7, 20.5.

HRMS (EI+)

Calculated for $\mathrm{C}_{13} \mathrm{H}_{13} \mathrm{O}_{2} \mathrm{~B}(\mathrm{M})^{+}$: $\quad 212.1009$

Found:

Boronic acid 10d. The general procedure was followed using 9d (226 mg, $0.686 \mathrm{mmol})$ and $1 \mathrm{M}$ aq. $\mathrm{NaOH}(2.06 \mathrm{~mL}, 2.06 \mathrm{mmol})$. The title compound was isolated as a pale green solid (131 mg, 88\%).

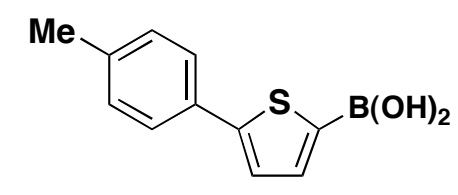

10d

$\operatorname{TLC}\left(\mathrm{Et}_{2} \mathrm{O}: \mathrm{CH}_{3} \mathrm{CN} 3: 1\right)$

$\mathrm{R}_{\mathrm{f}}=0.57$, visualized by $\mathrm{UV}$

${ }^{1} \mathrm{H}-\mathrm{NMR}\left(500 \mathrm{MHz}, d_{6}\right.$-DMSO: $\mathrm{D}_{2} \mathrm{O}$ 95:5)

$\delta 7.64(\mathrm{~d}, J=3.5 \mathrm{~Hz}, 1 \mathrm{H}), 7.57(\mathrm{~d}, J=8 \mathrm{~Hz}, 2 \mathrm{H}), 7.47(\mathrm{~d}, J=3.5 \mathrm{~Hz}, 1 \mathrm{H}), 7.24(\mathrm{~d}, J=8 \mathrm{~Hz}, 2 \mathrm{H})$, $2.32(\mathrm{~s}, 3 \mathrm{H})$.

${ }^{13} \mathrm{C}-\mathrm{NMR}\left(125 \mathrm{MHz}, d_{6}\right.$-DMSO:D $\left.2 \mathrm{O} 95: 5\right)$

ठ 148.9, 137.2, 137.2, 131.0, 129.6, 125.4, 124.1, 20.6.

HRMS (TOF ES+)

Calculated for $\mathrm{C}_{11} \mathrm{H}_{12} \mathrm{O}_{2} \mathrm{BS}(\mathrm{M}+\mathrm{H})^{+}: 219.0651$

Found:

219.0659

Boronic acid 10e. The general procedure was followed using 9e (243 mg, $0.696 \mathrm{mmol})$ and $1 \mathrm{M}$ aq. $\mathrm{NaOH}(2.09 \mathrm{~mL}, 2.09 \mathrm{mmol})$. The title compound was isolated as an off-white solid (138 $\mathrm{mg}, 83 \%)$.

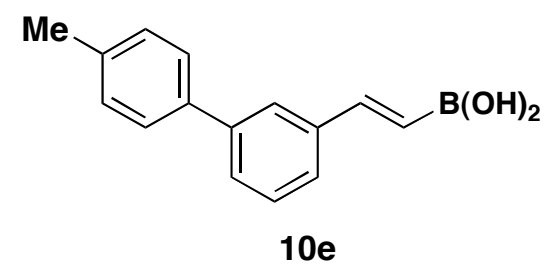

TLC (EtOAc)

$\mathrm{R}_{\mathrm{f}}=0.40$, stained by $\mathrm{KMnO}_{4}$

${ }^{1} \mathrm{H}-\mathrm{NMR}\left(500 \mathrm{MHz}, d_{6}\right.$-DMSO:D $\left.2 \mathrm{O} 95: 5\right)$

ठ 7.79-7.26 (m, 9H), $6.24(\mathrm{~d}, J=18.5 \mathrm{~Hz}, 1 \mathrm{H}), 2.35(\mathrm{~s}, 3 \mathrm{H})$.

${ }^{13} \mathrm{C}-\mathrm{NMR}\left(125 \mathrm{MHz}, d_{6}\right.$-DMSO:D $\left.2 \mathrm{O} 95: 5\right)$

ठ $145.8,140.4,138.1,136.9,136.9,129.5,129.3,126.5,126.5,125.2,124.7,20.6$.

HRMS (CI+) 
Calculated for $\mathrm{C}_{15} \mathrm{H}_{16} \mathrm{O}_{2} \mathrm{~B}(\mathrm{M}+\mathrm{H})^{+}: \quad 239.1243$

Found:

Boronic acid 10f. The general procedure was followed using 9f (202 mg, $0.56 \mathrm{mmol})$ and $1 \mathrm{M}$ aq. $\mathrm{NaOH}$ $(1.67 \mathrm{~mL}, 1.67 \mathrm{mmol})$. The title compound was isolated as an off-white solid $(127 \mathrm{mg}, 91 \%)$.

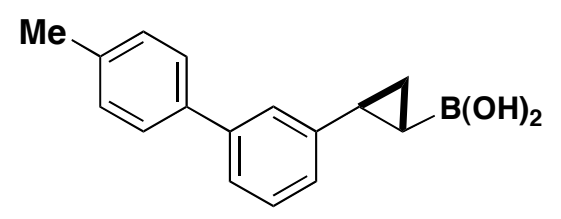

TLC (EtOAc)

$( \pm) 10 f$

$\mathrm{R}_{\mathrm{f}}=0.41$, visualized by $\mathrm{UV}$

${ }^{1} \mathrm{H}-\mathrm{NMR}\left(500 \mathrm{MHz}, \mathrm{CDCl}_{3}\right)$

ठ $7.49(\mathrm{~d}, J=8 \mathrm{~Hz}, 2 \mathrm{H}), 7.40-7.22(\mathrm{~m}, 5 \mathrm{H}), 7.07(\mathrm{~m}, 1 \mathrm{H}), 2.40(\mathrm{~s}, 3 \mathrm{H}), 2.29(\mathrm{~m}, 1 \mathrm{H}), 1.33(\mathrm{~m}$, $1 \mathrm{H}), 1.22(\mathrm{~m}, 1 \mathrm{H}), 0.44(\mathrm{~m}, 1 \mathrm{H})$.

${ }^{13} \mathrm{C}-\mathrm{NMR}\left(125 \mathrm{MHz}, \mathrm{CDCl}_{3}\right)$

ठ 145.2, 143.2, 141.3, 138.4, 137.0, 129.4, 128.7, 127.0, 124.6, 124.3.

HRMS (FAB+)

Calculated for $\mathrm{C}_{16} \mathrm{H}_{18} \mathrm{O}_{2} \mathrm{~B}(\mathrm{M}+\mathrm{H})^{+}: \quad 253.1400$

Found:

253.1401 
VII. Total synthesis of ratanhine (Scheme 3)

\section{Synthesis of building blocks 13-15.}

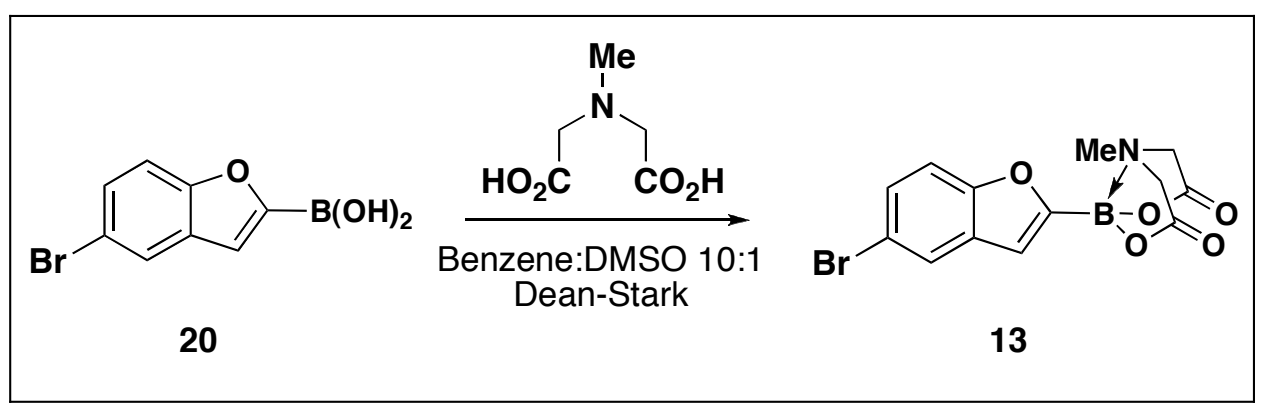

Building block 13. The general procedure for the synthesis of haloboronate esters (pg. S8) was followed using 5-bromo-2-benzofuranylboronic acid $(\mathbf{2 0})^{12}(1.33 \mathrm{~g}, 5.50 \mathrm{mmol}), \mathrm{N}$-methyliminodiacetic acid $(970$ $\mathrm{mg}, 6.60 \mathrm{mmol})$, benzene $(80 \mathrm{~mL})$ and DMSO $(8 \mathrm{~mL})$. The mixture was refluxed for $13 \mathrm{~h}$. The product was eluted using a gradient of $\mathrm{Et}_{2} \mathrm{O}: \mathrm{MeCN} 1: 1 \rightarrow 1: 2$. The title compound was isolated as an analytically pure, off-white, crystalline solid $(1.73 \mathrm{~g}, 90 \%)$.

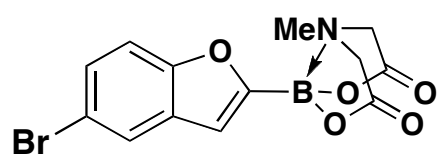

13

TLC (EtOAc)

$\mathrm{R}_{\mathrm{f}}=0.31$, stained by $\mathrm{KMnO}_{4}$

${ }^{1} \mathrm{H}-\mathrm{NMR}\left(500 \mathrm{MHz}, \mathrm{CD}_{3} \mathrm{CN}\right)$

$\delta 7.55(\mathrm{~d}, J=1.5 \mathrm{~Hz}, 1 \mathrm{H}), 7.42(\mathrm{~d}, J=8.5 \mathrm{~Hz}, 1 \mathrm{H}), 7.34(\mathrm{dd}, J=8.5,1.5 \mathrm{~Hz}, 1 \mathrm{H}), 7.05(\mathrm{~d}, J=1.5$

$\mathrm{Hz}, 1 \mathrm{H}), 6.50$ (dd, $J=16,1.5 \mathrm{~Hz}, 1 \mathrm{H}), 6.24(\mathrm{dq}, J=16,6.5 \mathrm{~Hz}, 1 \mathrm{H}), 4.11(\mathrm{~d}, J=17 \mathrm{~Hz}, 2 \mathrm{H}), 3.96$

(d, $J=17 \mathrm{~Hz}, 2 \mathrm{H}), 2.69$ (s, 3H), $1.85(\mathrm{dd}, J=6.5,1.5 \mathrm{~Hz}, 3 \mathrm{H})$.

${ }^{13} \mathrm{C}-\mathrm{NMR}\left(125 \mathrm{MHz}, \mathrm{CD}_{3} \mathrm{CN}\right)$

$\delta$ 169.0, 157.1, 131.3, 128.3, 124.8, 116.0, 115.2, 114.0, 62.6, 48.2.

${ }^{11} \mathrm{~B}-\mathrm{NMR}\left(100 \mathrm{MHz}, \mathrm{CD}_{3} \mathrm{CN}\right)$

$\delta 9.3$

HRMS (EI+)

Calculated for $\mathrm{C}_{13} \mathrm{H}_{11} \mathrm{O}_{5} \mathrm{NBrB}(\mathrm{M})^{+}: 350.9914$

Found:

350.9913

Elemental Analysis

Calculated: C, $44.36 \quad \mathrm{H}, 3.15 \quad \mathrm{~N}, 3.98 \quad \mathrm{Br}, 22.70$

Found: $\quad$ C, $44.43 \quad$ H, $2.81 \quad$ N,3.98 $\quad$ Br, 22.96

${ }^{12}$ Friedman, M. R.; Toyne, K. J.; Goodby, J. W.; Hird, M., J. Mater. Chem., 2001, 11, $2759-2772$. 
IR (thin film, $\mathrm{cm}^{-1}$ )

3012, 2964, 1754, 1467, 1446, 1282, 1233, 1199, 1140, 1078, 1047, 1002, 989, 802.

\section{Synthesis of building block 14 .}
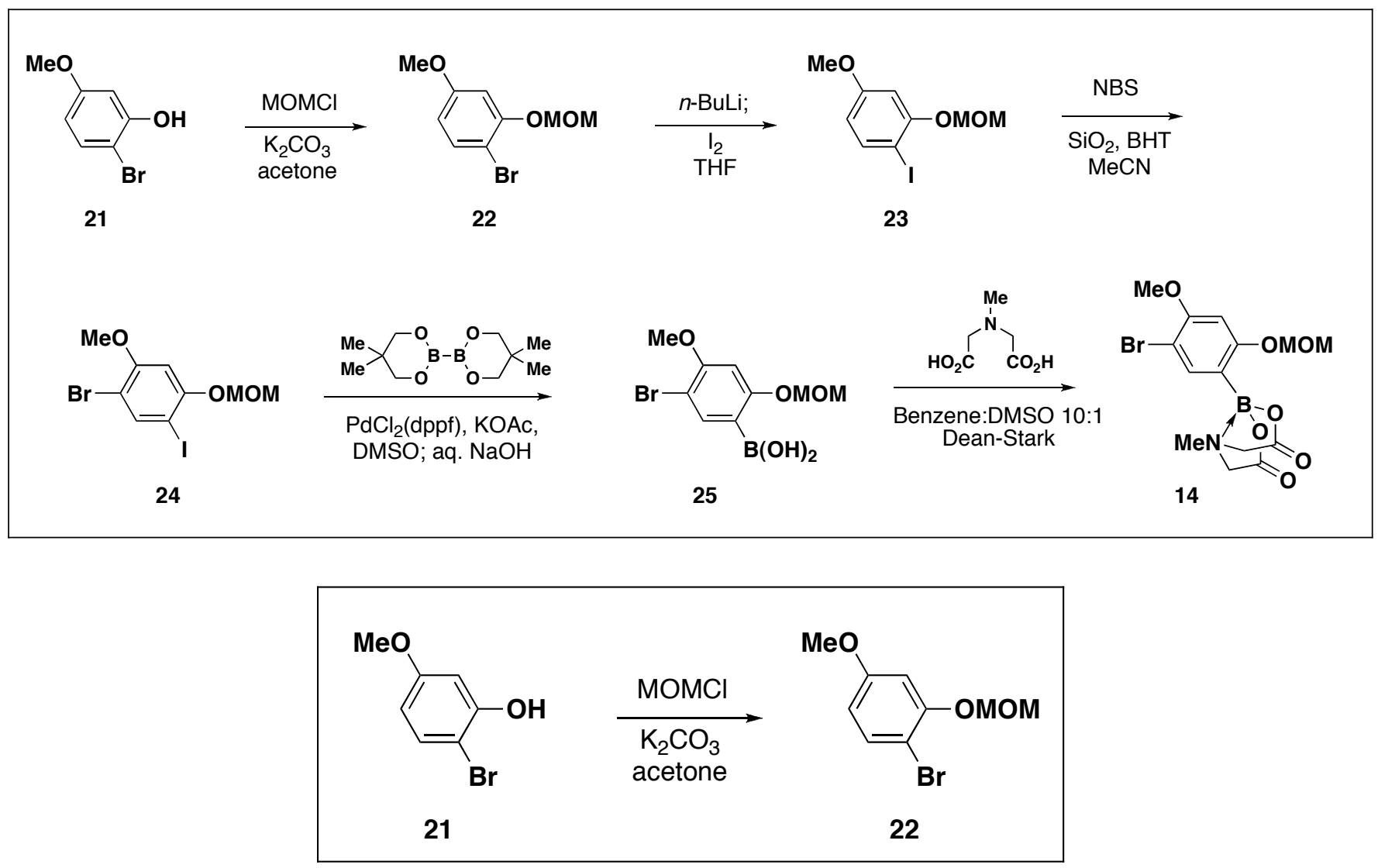

Methoxymethylether 22. To a stirred mixture of 2-bromo-5-methoxyphenol $(\mathbf{2 1})^{13}(2.19 \mathrm{~g}, 10.8 \mathrm{mmol})$ and $\mathrm{K}_{2} \mathrm{CO}_{3}$ (4.46 g, $\left.32.3 \mathrm{mmol}\right)$ in acetone $(55 \mathrm{~mL})$ was added chloromethyl methyl ether $(1.63 \mathrm{~mL}, 21.5$ $\mathrm{mmol}$ ). The mixture was refluxed for $3 \mathrm{~h}$ and then allowed to cool to $23{ }^{\circ} \mathrm{C}$. The mixture was filtered and the filtrate was concentrated in vacuo. The crude product was then purified by flash chromatography $\left(\mathrm{SiO}_{2}\right.$, hexanes:EtOAc 95:5) to provide 22 as colorless liquid $(2.43 \mathrm{~g}, 92 \%)$.

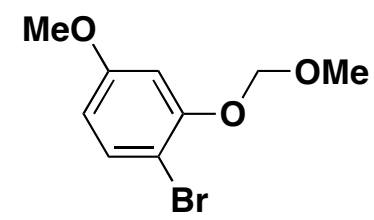

TLC (hexanes:EtOAc 95:5)

22

$\mathrm{R}_{\mathrm{f}}=0.17$, stained by anisaldehyde (red)

${ }^{13}$ Albert, J. S.; Aharony, D.; Andisik, D.; Barthlow, H.; Bernstein, P. R.; Bialecki, R. A.; Dedinas, R.; Dembofsky, B. T.; Hill, D.; Kirkland, K.; Koether, G. M.; Kosmider, B. J.; Ohnmacht, C.; Palmer, W.; Potts, W.; Rumsey, W.; Shen, L.; Shenvi, A.; Sherwood, S.; Warwick, P. J.; and Russell, K., J. Med. Chem., 2002, 45, 3972-3983. 
${ }^{1} \mathrm{H}-\mathrm{NMR}\left(500 \mathrm{MHz}, \mathrm{CDCl}_{3}\right)$

$\delta 7.40(\mathrm{~d}, J=9 \mathrm{~Hz}, 1 \mathrm{H}), 6.77(\mathrm{~d}, J=3 \mathrm{~Hz}, 1 \mathrm{H}), 6.46(\mathrm{dd}, J=9,3 \mathrm{~Hz}, 1 \mathrm{H}), 5.22(\mathrm{~s}, 2 \mathrm{H}), 3.77$ (s, $3 \mathrm{H}), 3.51(\mathrm{~s}, 3 \mathrm{H})$.

${ }^{13} \mathrm{C}-\mathrm{NMR}\left(125 \mathrm{MHz}, \mathrm{CDCl}_{3}\right)$

ठ 160.0, 154.4, 133.1, 108.1, 103.4, 103.2, 95.1, 56.3, 55.5.

HRMS (EI+)

Calculated for $\mathrm{C}_{9} \mathrm{H}_{11} \mathrm{O}_{3} \mathrm{Br}(\mathrm{M})^{+}$: 245.9892

Found:

245.9891

IR (thin film, $\mathrm{cm}^{-1}$ )

$3087,2998,2959,2938,2907,2835,1587,1483,1426,1393,1307,1281,1253,1219,1155$, 1086, 1056, 1023, 991, 841, 792.

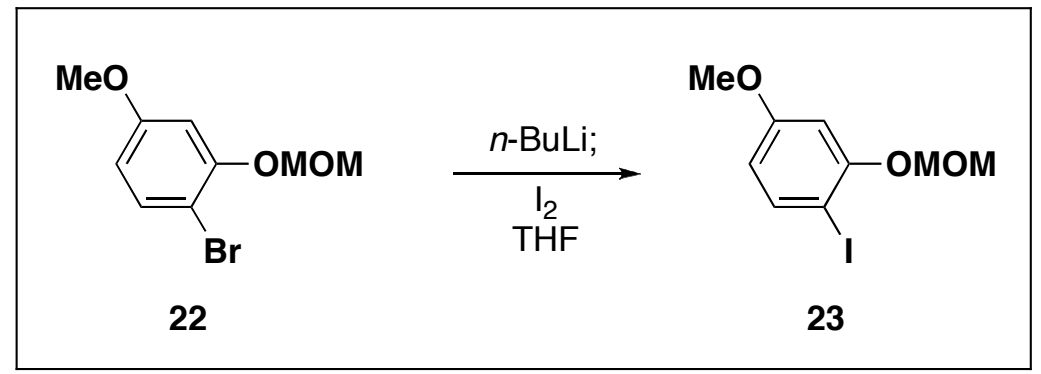

Aryliodide 23. ${ }^{14}$ To a stirred solution of $22(1.04 \mathrm{~g}, 4.23 \mathrm{mmol})$ in THF $(13 \mathrm{~mL})$ at $-95{ }^{\circ} \mathrm{C}\left(\right.$ hexanes/ $\left.\mathrm{N}_{2}\right)$ was added n-BuLi $(1.6 \mathrm{M}$ in hexanes, $2.91 \mathrm{~mL}, 4.65 \mathrm{mmol})$ and the resulting solution was stirred for 5 min. To this solution was then added by syringe a solution of $\mathrm{I}_{2}(1.28 \mathrm{~g}, 5.07 \mathrm{mmol})$ in THF $(8.5 \mathrm{~mL})$ until a yellow color persisted. The solution was then permitted to warm to $23{ }^{\circ} \mathrm{C}$ and concentrated in vасио. The residue was purified by flash chromatography $\left(\mathrm{SiO}_{2}\right.$, petroleum ether: $\left.\mathrm{Et}_{2} \mathrm{O} 8: 1\right)$ to provide $\mathbf{2 3}$ as a pale-orange oil (1.04 $\mathrm{g}, 84 \%)$.

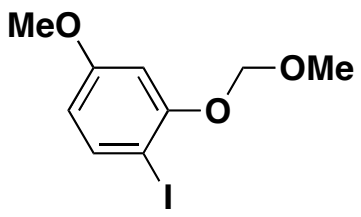

23

TLC (petroleum ether: $\mathrm{Et}_{2} \mathrm{O} 8: 1$ )

$\mathrm{R}_{\mathrm{f}}=0.16$, stained by anisaldehyde (red)

${ }^{1} \mathrm{H}-\mathrm{NMR}\left(500 \mathrm{MHz}, \mathrm{CDCl}_{3}\right)$

$\delta 7.62(\mathrm{~d}, J=8.5 \mathrm{~Hz}, 1 \mathrm{H}), 6.70(\mathrm{~d}, J=3 \mathrm{~Hz}, 1 \mathrm{H}), 6.39(\mathrm{dd}, J=8.5,3 \mathrm{~Hz}, 1 \mathrm{H}), 5.22(\mathrm{~s}, 2 \mathrm{H}), 3.78$ $(\mathrm{s}, 3 \mathrm{H}), 3.51(\mathrm{~s}, 3 \mathrm{H})$.

${ }^{13} \mathrm{C}-\mathrm{NMR}\left(125 \mathrm{MHz}, \mathrm{CDCl}_{3}\right)$

$\delta 161.2,156.8,139.1,109.0,102.3,95.0,75.8,56.4,55.5$.

${ }^{14}$ An alternative preparation of $\mathbf{2 3}$ has been previously described: Tsukayama, M.; Hideyuki, U.; Kunugi, A.; Nozaki, H. Heterocycles, 1997, 45, 1131-1142. 
HRMS (EI+):

Calculated for $\mathrm{C}_{9} \mathrm{H}_{11} \mathrm{O}_{3} \mathrm{I}(\mathrm{M})^{+}$: $\quad 293.9753$

Found:

IR (thin film, $\mathrm{cm}^{-1}$ )

2999, 2959, 2936, 2904, 2835, 1580, 1477, 1424, 1392, 1304, 1279, 1253, 1218, 1162, 1085, 1052, 991, 924, 840, 791.

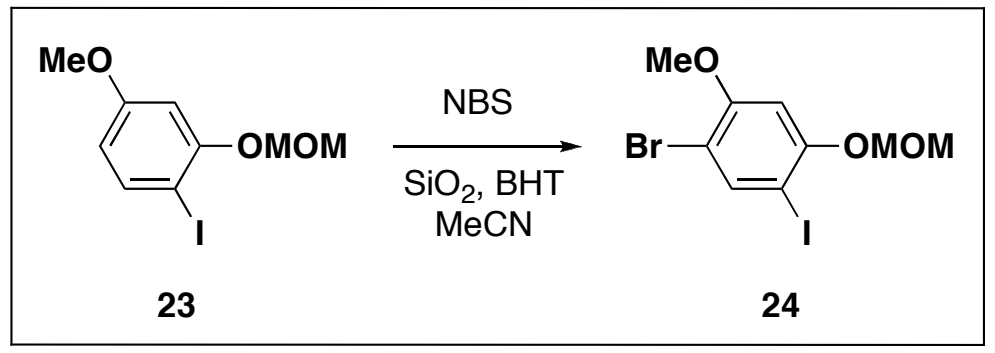

Aryl bromide 24. To a stirred solution of $23(5.24 \mathrm{~g}, 17.8 \mathrm{mmol})$ in MeCN (55 mL) was added silica gel (1.32 g), 2,6-di-tert-butyl-4-hydroxytoluene (60 mg), and then $N$-bromosuccinimide (3.17 g, $17.8 \mathrm{mmol})$. The mixture was stirred at $23{ }^{\circ} \mathrm{C}$ for 1 hour and then filtered. The filtrate was concentrated in vacuo and the residue was dissolved in $\mathrm{CH}_{2} \mathrm{Cl}_{2}(100 \mathrm{~mL})$. To this solution was added water $(100 \mathrm{~mL})$ and the resulting mixture was vigorously stirred for $5 \mathrm{~min}$. The layers were then separated and the aq. phase was extracted with $\mathrm{CH}_{2} \mathrm{Cl}_{2}(2 \times 100 \mathrm{~mL})$. The combined organics were dried over $\mathrm{MgSO}_{4}$ and concentrated in vacuo. The residue was purified by flash-column chromatography $\left(\mathrm{SiO}_{2}\right.$, petroleum ether: $\left.\mathrm{Et}_{2} \mathrm{O} 8: 1\right)$ to provide 24 as a yellow oil (5.05 g, 76\%).

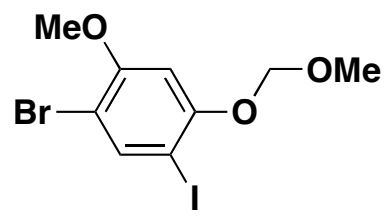

24

TLC (petroleum ether: $\mathrm{Et}_{2} \mathrm{O} 8: 1$ )

$\mathrm{R}_{\mathrm{f}}=0.17$, stained by anisaldehyde (red)

${ }^{1} \mathrm{H}-\mathrm{NMR}\left(500 \mathrm{MHz}, \mathrm{CDCl}_{3}\right)$

$\delta 7.85(\mathrm{~s}, 1 \mathrm{H}), 6.73(\mathrm{~s}, 1 \mathrm{H}), 5.23(\mathrm{~s}, 2 \mathrm{H}), 3.87(\mathrm{~s}, 3 \mathrm{H}), 3.52(\mathrm{~s}, 3 \mathrm{H})$.

${ }^{13} \mathrm{C}-\mathrm{NMR}\left(\mathrm{CD}_{3} \mathrm{CN}\right)$

ठ $157.0,156.6,141.3,104.7,100.1,95.4,75.5,56.5,56.4$.

HRMS (EI+):

Calculated for $\mathrm{C}_{9} \mathrm{H}_{10} \mathrm{O}_{3} \mathrm{BrI}(\mathrm{M})^{+}$: $\quad 371.8858$

Found:

371.8859

IR (thin film, $\mathrm{cm}^{-1}$ )

2999, 2963, 2937, 2906, 2853, 2826, 1575, 1470, 1439, 1408, 1358, 1283, 1268, 1217, 1151, 1086, 1056, 994, 993, 878, 818. 


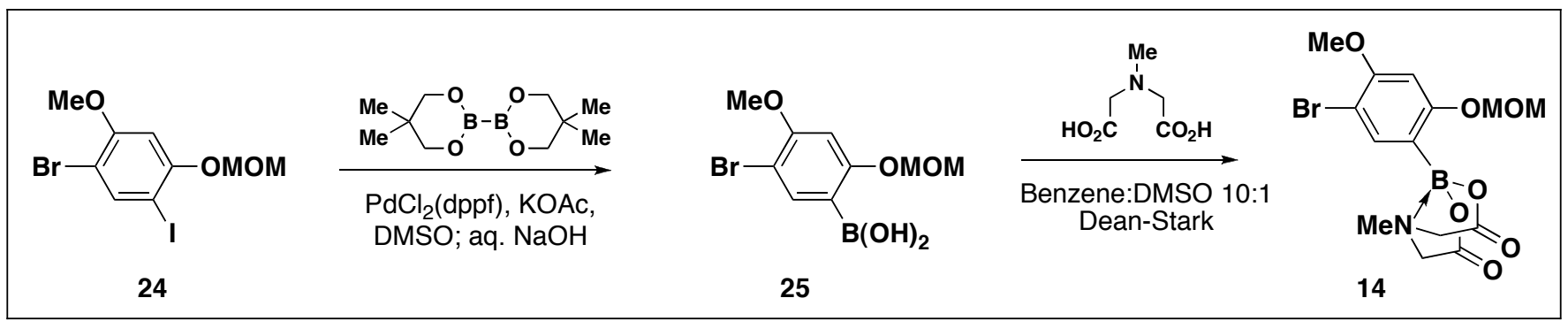

Building block 14. In a glove box, to a $40 \mathrm{~mL}$ I-Chem vial equipped with a stir bar and containing 24 (500 mg, $1.34 \mathrm{mmol}$ ) was added potassium acetate (395 mg, $4.02 \mathrm{mmol}$ ), bis(neopentylglycolato)diboron (363 mg, $1.61 \mathrm{mmol}$ ) and $\mathrm{PdCl}_{2}(\mathrm{dppf})(33 \mathrm{mg}, 0.040 \mathrm{mmol})$. The vial was sealed with a septum cap and then removed from the glove box. To the vial was then added DMSO $(11 \mathrm{~mL})$ and the resulting mixture was sealed under an atmosphere of argon and stirred at $80^{\circ} \mathrm{C}$ for $13 \mathrm{~h}$. The mixture was then allowed to cool to $23{ }^{\circ} \mathrm{C}$ and $1 \mathrm{M}$ aq. $\mathrm{NaOH}$ was added $(0.9 \mathrm{~mL}, 0.9 \mathrm{mmol})$. The mixture was stirred at $23^{\circ} \mathrm{C}$ for 10 minutes and then diluted with saturated aq. $\mathrm{NH}_{4} \mathrm{Cl}(50 \mathrm{~mL})$, water $(50 \mathrm{~mL})$, and $\mathrm{Et}_{2} \mathrm{O}(100 \mathrm{~mL})$. The layers were separated and the organic phase was washed with water ( 3 x $100 \mathrm{~mL}$ ), dried over $\mathrm{MgSO}_{4}$, and concentrated in vacuo. The residue was thrice dissolved in $\mathrm{MeCN}$ and concentrated in vacuo to afford a crude sample of boronic acid 25 as a light brown solid (343 mg): TLC (EtOAc) $\mathrm{R}_{\mathrm{f}}=0.50$, stained by $\mathrm{KMnO}_{4} ;{ }^{1} \mathrm{H}-\mathrm{NMR}\left(400 \mathrm{MHz}, \mathrm{CDCl}_{3}\right) \delta 7.97$ (s, 1H), 6.75 (s, 1H), 5.97 (s, 2H), 5.29 (s, 2H), $3.91(\mathrm{~s}, 3 \mathrm{H})$, $3.52(\mathrm{~s}, 3 \mathrm{H})$. To this crude boronic acid dissolved in benzene:DMSO (10:1) was added $N$ methyliminodiacetic acid $(210 \mathrm{mg}, 1.43 \mathrm{mmol})$. The flask was fitted with a Dean-Stark trap and a reflux condenser and the mixture was refluxed with stirring for $11 \mathrm{~h}$ followed by concentration in vacuo. The resulting crude product was adsorbed onto Florisil gel from a MeCN solution. The resulting powder was dry-loaded on top of a silica gel column slurry-packed with $\mathrm{Et}_{2} \mathrm{O}$. The column was flushed with a copious volume of $\mathrm{Et}_{2} \mathrm{O}$ and then the product was eluted with $\mathrm{Et}_{2} \mathrm{O}: \mathrm{MeCN}$ 1:1 to yield building block 14 as an offwhite solid (365 mg, 68\% yield over two steps).

$\mathrm{TLC}\left(\mathrm{Et}_{2} \mathrm{O}: \mathrm{CH}_{3} \mathrm{CN} 3: 1\right)$

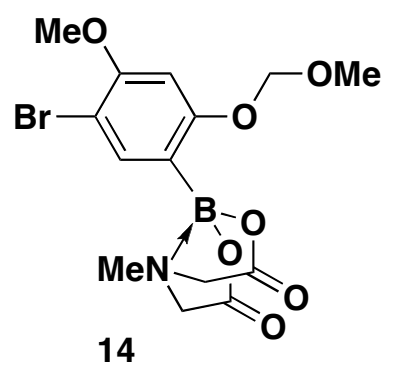

$\mathrm{R}_{\mathrm{f}}=0.44$, stained by $\mathrm{KMnO}_{4}$

${ }^{1} \mathrm{H}-\mathrm{NMR}\left(500 \mathrm{MHz}, \mathrm{CD}_{3} \mathrm{CN}\right)$

ठ $7.62(\mathrm{~s}, 1 \mathrm{H}), 6.76(\mathrm{~s}, 1 \mathrm{H}), 5.18(\mathrm{~s}, 2 \mathrm{H}), 4.06(\mathrm{~d}, J=17 \mathrm{~Hz}, 2 \mathrm{H}), 3.94(\mathrm{~d}, J=17 \mathrm{~Hz}, 2 \mathrm{H}), 3.85(\mathrm{~s}$, $3 \mathrm{H}), 3.39(\mathrm{~s}, 3 \mathrm{H}), 2.64(\mathrm{~s}, 3 \mathrm{H})$.

${ }^{13} \mathrm{C}-\mathrm{NMR}\left(125 \mathrm{MHz}, \mathrm{CD}_{3} \mathrm{CN}\right)$

ठ 169.5, 161.6, 158.6, 139.0, 103.6, 100.1, 95.1, 64.4, 64.2, 56.9, 48.4 .

${ }^{11} \mathrm{~B}-\mathrm{NMR}\left(100 \mathrm{MHz}, \mathrm{CD}_{3} \mathrm{CN}\right)$

ठ 11.9 
HRMS (EI+)

Calculated for $\mathrm{C}_{14} \mathrm{H}_{17} \mathrm{O}_{7} \mathrm{NBrB}(\mathrm{M})^{+}: 401.0281$

Found:

401.0281

IR (thin film, $\mathrm{cm}^{-1}$ )

3008, 2963, 2944, 2904, 1768, 1596, 1558, 1488, 1446, 1367, 1337, 1276, 1198, 1164, 1147,

$1048,1035,1006,951,858$.

Synthesis of building block 15 .
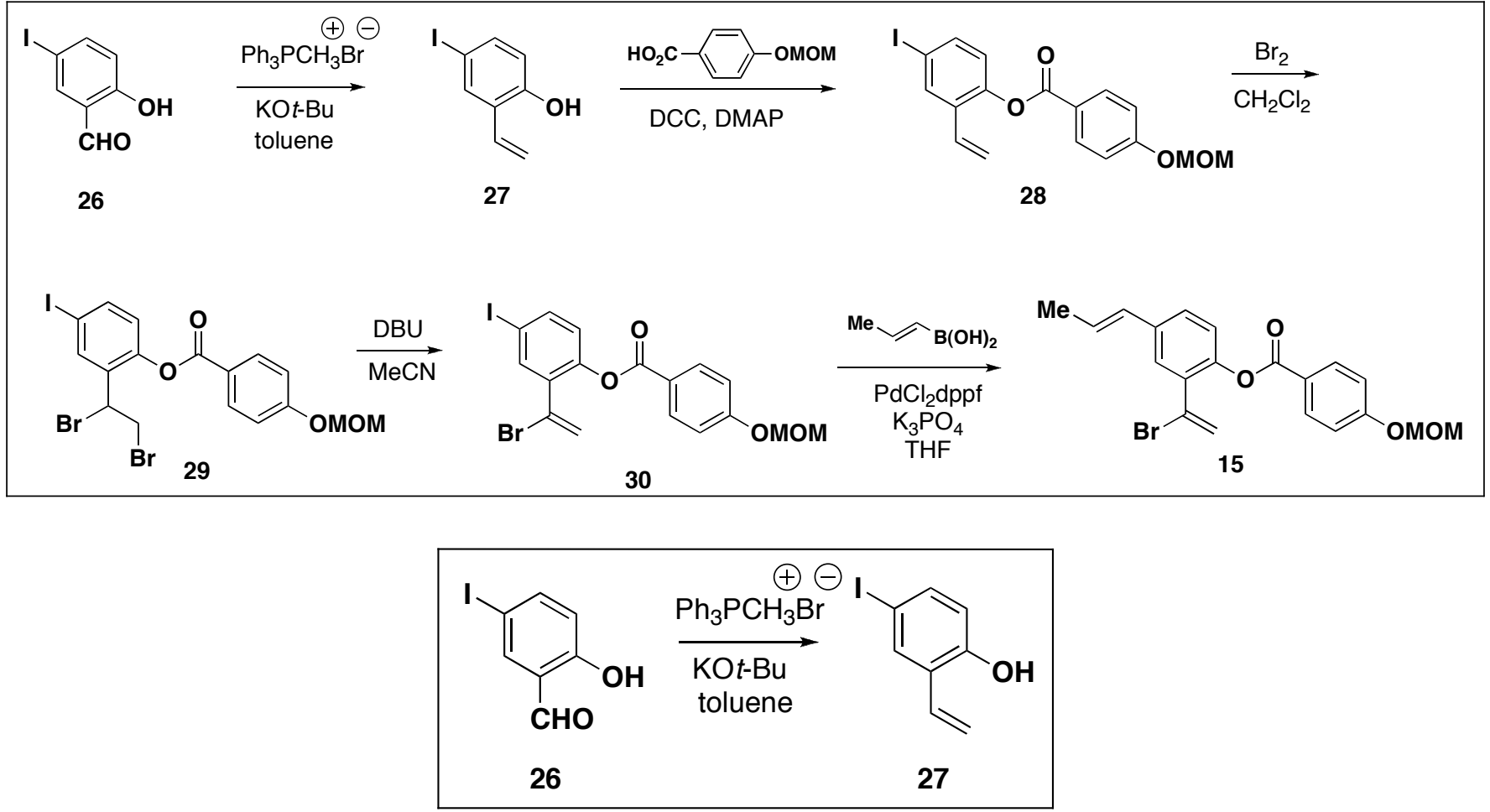

Olefin 27. ${ }^{15}$ To a mixture of methyltriphenylphosphonium bromide (14.08 g, $\left.39.4 \mathrm{mmol}\right)$ in toluene at 23 ${ }^{\circ} \mathrm{C}$ was added a solution of potassium tert-butoxide $(4.47 \mathrm{~g}, 39.8 \mathrm{mmol})$ in THF (60 mL) dropwise via cannula, and the resulting mixture was allowed to stir at $23{ }^{\circ} \mathrm{C}$ for 4 hours. The resulting yellow mixture was cooled to $-78^{\circ} \mathrm{C}$ and a solution of 4-iodo-salicylaldehyde (26) (4.35 g, $\left.17.5 \mathrm{mmol}\right)$ in toluene (40 mL) was added dropwise via cannula. The resulting mixture was allowed to slowly warm to $23{ }^{\circ} \mathrm{C}$ and was stirred at that temperature for 12 hours. The reaction was then quenched with the addition of saturated aq. ammonium chloride $(100 \mathrm{~mL})$. The resulting mixture was then diluted with water $(200 \mathrm{~mL})$ and extracted with $\mathrm{Et}_{2} \mathrm{O}(3 \times 100 \mathrm{~mL})$. The combined organic fractions were then washed with brine $(100 \mathrm{~mL})$, dried over magnesium sulfate, and concentrated in vacuo. Purification by flash chromatography $\left(\mathrm{SiO}_{2}\right.$, hexanes:ethyl acetate $7: 1 \rightarrow 1: 1)$ yielded 27 as a colorless solid $(4.0 \mathrm{~g}, 98 \%)$.

${ }^{15}$ For related transformations, see: Gligorich, K. M.; Schultz, M. J.; Sigman, M. S. J. Am. Chem. Soc. 2006; 128, $2794-2795$. 


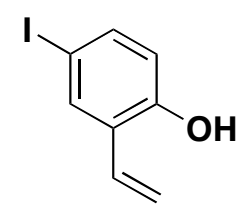

27

TLC (hexanes:ethyl acetate 4:1)

$\mathrm{R}_{\mathrm{f}}=0.34$, stained by $\mathrm{KMnO}_{4}$

${ }^{1} \mathrm{H}-\mathrm{NMR}\left(500 \mathrm{MHz}, \mathrm{CDCl}_{3}\right)$

$\delta 7.67(\mathrm{~d}, J=2 \mathrm{~Hz}, 1 \mathrm{H}), 7.41(\mathrm{dd}, J=8.5,2 \mathrm{~Hz}, 1 \mathrm{H}), 6.82(\mathrm{dd}, J=18,11 \mathrm{~Hz}), 6.57(\mathrm{~d}, J=8.5 \mathrm{~Hz}$, $1 \mathrm{H}), 5.73(\mathrm{dd}, J=18,1 \mathrm{~Hz}, 1 \mathrm{H}), 5.39$ (dd, $J=11,1 \mathrm{~Hz}, 1 \mathrm{H}), 4.98$ (br s, $1 \mathrm{H})$.

${ }^{13} \mathrm{C}-\mathrm{NMR}\left(125 \mathrm{MHz}, \mathrm{CDCl}_{3}\right)$

$\delta 152.5,137.4,135.9,130.1,127.4,118.0,117.2,83.1$.

HRMS (EI+)

Calculated for $\mathrm{C}_{8} \mathrm{H}_{7} \mathrm{OI}(\mathrm{M})^{+}$: $\quad 245.9542$

Found:

245.9542

IR (thin film, $\mathrm{cm}^{-1}$ )

$3248,1593,1486,1431,1408,1269,1237,1172,1110,995,916,884,809$.

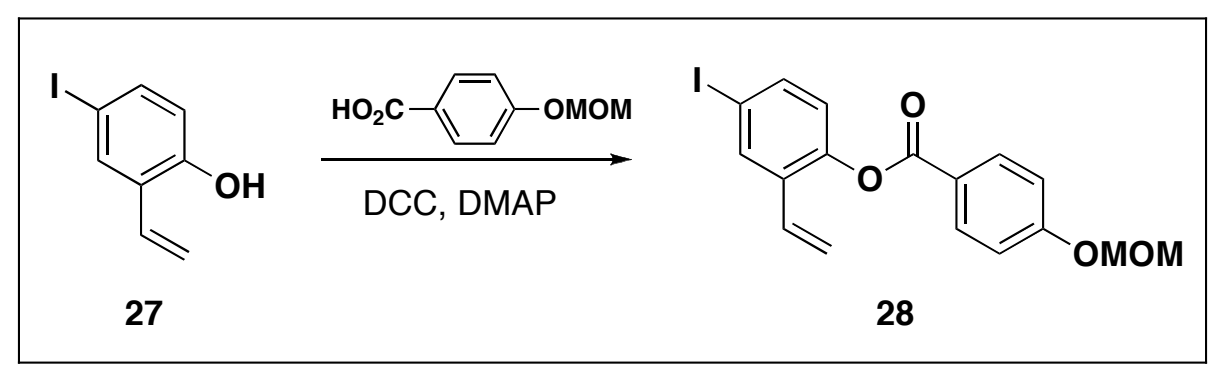

Benzoate ester 28. To a stirred solution of 27, 4-(methoxymethoxy)benzoic acid, and DCC in methylene chloride at $23{ }^{\circ} \mathrm{C}$ was added DMAP, and the resulting mixture was stirred at $23{ }^{\circ} \mathrm{C}$ for 21 hours. The reaction mixture was then filtered over celite and concentrated in vacuo. Purification by flash chromatography ( $\mathrm{SiO}_{2}$, hexanes:ethyl acetate 5:1) yielded $\mathbf{2 8}$ as a colorless solid (4.6 g, 79\%).

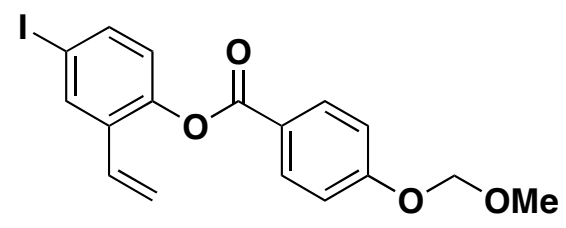

28

TLC (hexanes:ethyl acetate 4:1)

$\mathrm{R}_{\mathrm{f}}=0.37$, stained by $\mathrm{KMnO}_{4}$

${ }^{1} \mathrm{H}-\mathrm{NMR}\left(500 \mathrm{MHz}, \mathrm{CDCl}_{3}\right.$ ) 
$\delta 8.17(\mathrm{~d}, J=9 \mathrm{~Hz}, 2 \mathrm{H}), 7.93(\mathrm{~d}, J=2 \mathrm{~Hz}, 1 \mathrm{H}), 7.63(\mathrm{dd}, J=8.5,2 \mathrm{~Hz}, 1 \mathrm{H}), 7.15(\mathrm{~d}, J=9 \mathrm{~Hz}$, $2 \mathrm{H}), 6.93(\mathrm{~d}, J=8.5 \mathrm{~Hz}, 1 \mathrm{H}), 6.70(\mathrm{dd}, J=18,11 \mathrm{~Hz}, 1 \mathrm{H}), 5.77(\mathrm{dd}, J=18,1 \mathrm{~Hz}, 1 \mathrm{H}), 5.34(\mathrm{dd}, J$ $=11,1 \mathrm{~Hz}, 1 \mathrm{H}), 5.28(\mathrm{~s}, 2 \mathrm{H}), 3.52(\mathrm{~s}, 3 \mathrm{H})$

${ }^{13} \mathrm{C}-\mathrm{NMR}\left(125 \mathrm{MHz}, \mathrm{CDCl}_{3}\right)$

ठ 164.2, 161.7, 148.1, 137.4, 135.4, 132.8, 132.3, 129.1, 124.8, 122.1, 117.5, 115.9, 94.1, 90.4,

56.3 .

HRMS (EI+)

Calculated for $\mathrm{C}_{17} \mathrm{H}_{15} \mathrm{O}_{4} \mathrm{I}(\mathrm{M})^{+}: \quad 410.0015$

Found: $\quad 410.0020$

IR (thin film, $\mathrm{cm}^{-1}$ )

2956, 2900, 1736, 1604, 1509, 1473, 1420, 1318, 1259, 1244, 1213, 1166, 1152, 1105, 1081, $1061,986,922,850,763$.

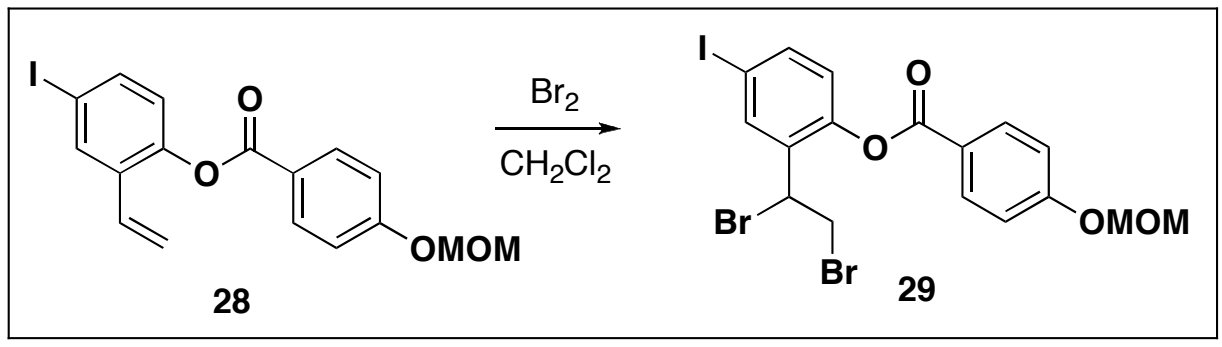

Dibromide 29. To a stirred solution of $\mathbf{2 8}$ (azeotropically dried with 2 x $50 \mathrm{~mL}$ benzene) in methylene chloride at $0{ }^{\circ} \mathrm{C}$ was added bromine dropwise via syringe over 5 minutes. The resulting solution was stirred at $0{ }^{\circ} \mathrm{C}$ for an additional 5 minutes and then concentrated in vacuo at $0{ }^{\circ} \mathrm{C}$ over 30 min. Residual bromine was removed via co-evaporation with $3 \times 15 \mathrm{~mL}$ of methylene chloride at $0{ }^{\circ} \mathrm{C}$. The resulting crude product mixture was then purified by flash chromatography $\left(\mathrm{SiO}_{2}\right.$, hexanes:ethyl acetate 5:1 $\rightarrow$ 2:1) to yield 29 as a colorless solid $(3.7 \mathrm{~g}, 59 \%)$

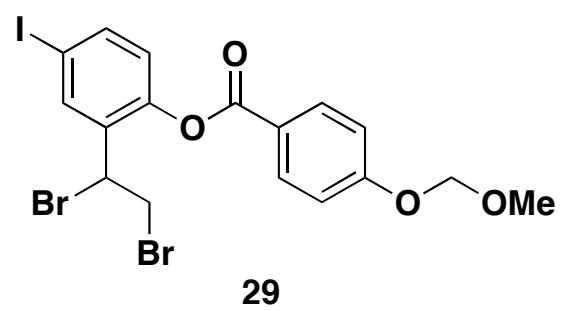

TLC (hexanes:ethyl acetate 4:1)

$\mathrm{R}_{\mathrm{f}}=0.34$, stained by $\mathrm{KMnO}_{4}$

${ }^{1} \mathrm{H}-\mathrm{NMR}\left(400 \mathrm{MHz}, \mathrm{CDCl}_{3}\right)$

$\delta 8.17(\mathrm{~d}, J=8.8 \mathrm{~Hz}, 2 \mathrm{H}), 7.82(\mathrm{~d}, J=2 \mathrm{~Hz}, 1 \mathrm{H}), 7.72(\mathrm{dd}, J=8.8,2 \mathrm{~Hz}, 1 \mathrm{H}), 7.16(\mathrm{~d}, J=8.8 \mathrm{~Hz}$, $2 \mathrm{H}), 7.03(\mathrm{~d}, J=8.8 \mathrm{~Hz}, 1 \mathrm{H}), 5.28(\mathrm{~m}, 3 \mathrm{H}), 4.01(\mathrm{~m}, 2 \mathrm{H}), 3.51(\mathrm{~s}, 3 \mathrm{H})$.

${ }^{13} \mathrm{C}-\mathrm{NMR}\left(125 \mathrm{MHz}, \mathrm{CDCl}_{3}\right)$

$\delta 163.5,161.9,148.5,138.9,137.2,132.9,132.4,125.3,121.8,116.1,94.1,90.0,56.3,42.6,33.4$.

HRMS (EI+) 
Calculated for $\mathrm{C}_{17} \mathrm{H}_{15} \mathrm{O}_{4} \mathrm{Br}_{2} \mathrm{I}(\mathrm{M})^{+}: \quad 567.8382$

Found:

567.8378

IR (thin film, $\mathrm{cm}^{-1}$ )

2959, 2899, 2854, 2826, 1736, 1604, 1581, 1509, 1480, 1441, 1421, 1397, 1318, 1260, 1245, $1217,1169,1152$, 1133, 1106, 1081, 1053, 1009, 986, 919, 870, 849, 809, 761, 733, 691, 649, 604.

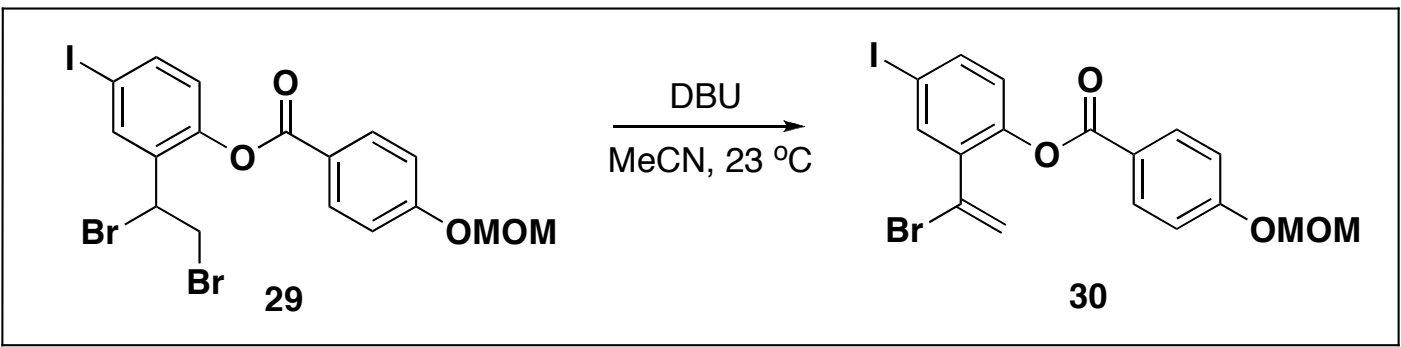

Vinylbromide 30. To a stirred solution of $29(3.61 \mathrm{~g}, 6.33 \mathrm{mmol}$, azeotropically dried with acetonitrile) in acetonitrile $(75 \mathrm{~mL})$ at $23{ }^{\circ} \mathrm{C}$ was added DBU (1.928 g, $12.7 \mathrm{mmol}, 2.0$ eq.) dropwise via syringe over 2 minutes. The resulting mixture was stirred at $23{ }^{\circ} \mathrm{C}$ for $25 \mathrm{~min}$. The reaction was then quenched with the addition of $1 \mathrm{M}$ aq. $\mathrm{HCl}(200 \mathrm{~mL})$ and the resulting mixture was extracted with ethyl acetate $(1 \mathrm{x} 200$ $\mathrm{mL}$ and $2 \times 125 \mathrm{~mL})$. The combined organic fractions were washed with brine $(100 \mathrm{~mL})$, dried over magnesium sulfate, and concentrated in vacuo. Flash chromatography $\left(\mathrm{SiO}_{2}\right.$, petroleum ether:Et $\left.\mathrm{O}_{2} 3: 1\right)$ yielded 30 as a colorless oil (3.01 g, 97\%).

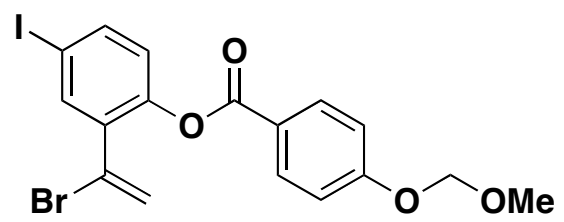

30

TLC (hexanes:ethyl acetate 4:1)

$\mathrm{R}_{\mathrm{f}}=0.37$, stained by $\mathrm{KMnO}_{4}$

${ }^{1} \mathrm{H}-\mathrm{NMR}\left(400 \mathrm{MHz}, \mathrm{CDCl}_{3}\right)$

$\delta 8.15(\mathrm{~d}, J=8.8 \mathrm{~Hz}, 2 \mathrm{H}), 7.79(\mathrm{~d}, J=2 \mathrm{~Hz}, 1 \mathrm{H}), 7.70(\mathrm{dd}, J=8.4,2 \mathrm{~Hz}, 1 \mathrm{H}), 7.13(\mathrm{~d}, J=8.8 \mathrm{~Hz}$, $2 \mathrm{H}), 6.98,(\mathrm{~d}, J=8.4 \mathrm{~Hz}, 1 \mathrm{H}), 5.91(\mathrm{~d}, J=2 \mathrm{~Hz}, 1 \mathrm{H}), 5.84(\mathrm{~d}, J=2 \mathrm{~Hz}, 1 \mathrm{H}), 5.26(\mathrm{~s}, 2 \mathrm{H}), 3.50$ (s, $3 \mathrm{H})$.

${ }^{13} \mathrm{C}-\mathrm{NMR}\left(125 \mathrm{MHz}, \mathrm{CDCl}_{3}\right)$

ठ 164.0, 161.7, 147.7, 138.9, 138.9, 135.4, 132.5, 125.2, 123.0, 122.6, 122.1, 115.9, 94.1, 89.5, 56.3 .

HRMS (EI+)

Calculated for $\mathrm{C}_{17} \mathrm{H}_{14} \mathrm{O}_{4} \mathrm{BrI}(\mathrm{M})^{+}$: $\quad 487.9120$

Found:

487.9125

IR (thin film, $\mathrm{cm}^{-1}$ ) 
2954, 2924, 2900, 2853, 2826, 1737, 1604, 1582, 1509, 1476, 1318, 1257, 1244, 1217, 1189, $1168,1152,1123,1081,1054,987,923,873,848,761,690$.

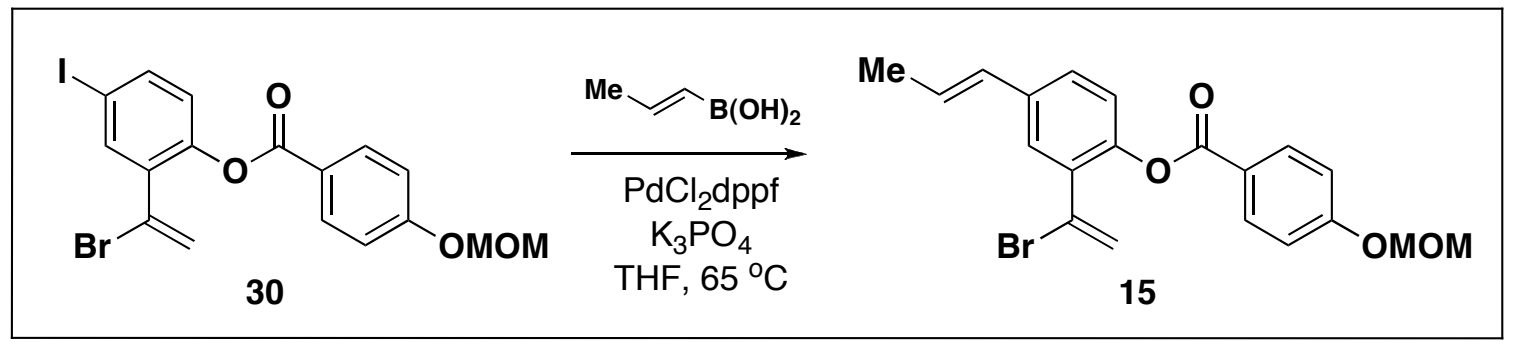

Building block 15. In a glove box, to a $40 \mathrm{~mL}$ I-Chem vial equipped with a stir bar and containing 30 $\left(0.8695 \mathrm{~g}, 1.78 \mathrm{mmol}\right.$; azeotropically-dried with $3 \mathrm{X} 5 \mathrm{~mL}$ benzene) was added $\mathrm{K}_{3} \mathrm{PO}_{4}(0.7548 \mathrm{~g}, 3.56$ $\mathrm{mmol})$, propenylboronic acid $(0.183 \mathrm{~g}, 2.13 \mathrm{mmol})$ as a solution in THF $(3.6 \mathrm{~mL})$, and $\mathrm{PdCl}_{2} \mathrm{dppf}(72.6$ $\mathrm{mg}, 0.09 \mathrm{mmol}$ ) as a solid. An additional $6.8 \mathrm{~mL}$ of THF was added and the resulting mixture was sealed with a PTFE-lined cap and maintained at $65^{\circ} \mathrm{C}$ with stirring for 15 hours. The reaction mixture was then allowed to cool to $23{ }^{\circ} \mathrm{C}$, quenched with the addition of $1 \mathrm{M} \mathrm{pH} 7$ phosphate buffer $(60 \mathrm{~mL})$, and extracted with diethyl ether ( 3 X $60 \mathrm{~mL})$. The combined organic fractions were then washed with water $(20 \mathrm{~mL})$ and brine $(40 \mathrm{~mL})$, dried over $\mathrm{MgSO}_{4}$, and concentrated in vacuo. Flash chromatography $\left(\mathrm{SiO}_{2}\right.$, toluene) yielded the desired product as a colorless oil (0.4994 g, $1.24 \mathrm{mmol}, 70 \%)$.

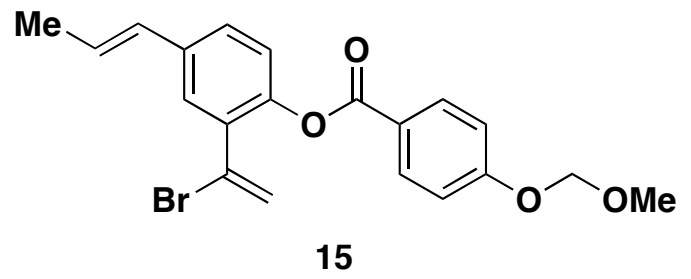

TLC (Toluene)

$\mathrm{R}_{\mathrm{f}}=0.18$, stained by $p$-anisaldehyde

${ }^{1} \mathrm{H}-\mathrm{NMR}\left(500 \mathrm{MHz}, \mathrm{CDCl}_{3}\right)$

$\delta 8.17(\mathrm{~d}, J=9 \mathrm{~Hz}, 2 \mathrm{H}), 7.40(\mathrm{~d}, J=2.5 \mathrm{~Hz}, 1 \mathrm{H}), 7.35(\mathrm{dd}, J=8,2.5 \mathrm{~Hz}, 1 \mathrm{H}), 7.13(\mathrm{~d}, J=8 \mathrm{~Hz}$, $1 \mathrm{H}), 7.13(\mathrm{~d}, J=9 \mathrm{~Hz}, 2 \mathrm{H}), 6.39(\mathrm{dd}, J=15.5,1.5 \mathrm{~Hz}, 1 \mathrm{H}), 6.25(\mathrm{dq}, J=15.5,6.5 \mathrm{~Hz}, 1 \mathrm{H}), 5.89$ $(\mathrm{d}, J=1.5 \mathrm{~Hz}, 1 \mathrm{H}), 5.82(\mathrm{~d}, J=1.5 \mathrm{~Hz}, 1 \mathrm{H}), 5.26(\mathrm{~s}, 2 \mathrm{H}), 3.51(\mathrm{~s}, 3 \mathrm{H}), 1.90(\mathrm{dd}, J=6.5,1.5 \mathrm{~Hz}$, $3 \mathrm{H})$.

${ }^{13} \mathrm{C}-\mathrm{NMR}\left(125 \mathrm{MHz}, \mathrm{CDCl}_{3}\right)$

$\delta 164.4,161.5,146.3,135.9,133.2,132.4,129.5,127.6,127.2,126.9,124.6,123.2,122.6,122.1$, $115.8,94.1,56.3,18.5$.

HRMS (TOF ES+)

Calculated for $\mathrm{C}_{20} \mathrm{H}_{20} \mathrm{O}_{4} \mathrm{Br}(\mathrm{M}+\mathrm{H})^{+}: 403.0545$

Found:

403.0557

IR (thin film, $\mathrm{cm}^{-1}$ )

2952, 2910, 1736, 1605, 1509, 1487, 1263, 1244, 1200, 1168, 1153, 1081, 1062, 985, 849, 762. 
Iterative Suzuki-Miyaura coupling of building blocks 12 - 15

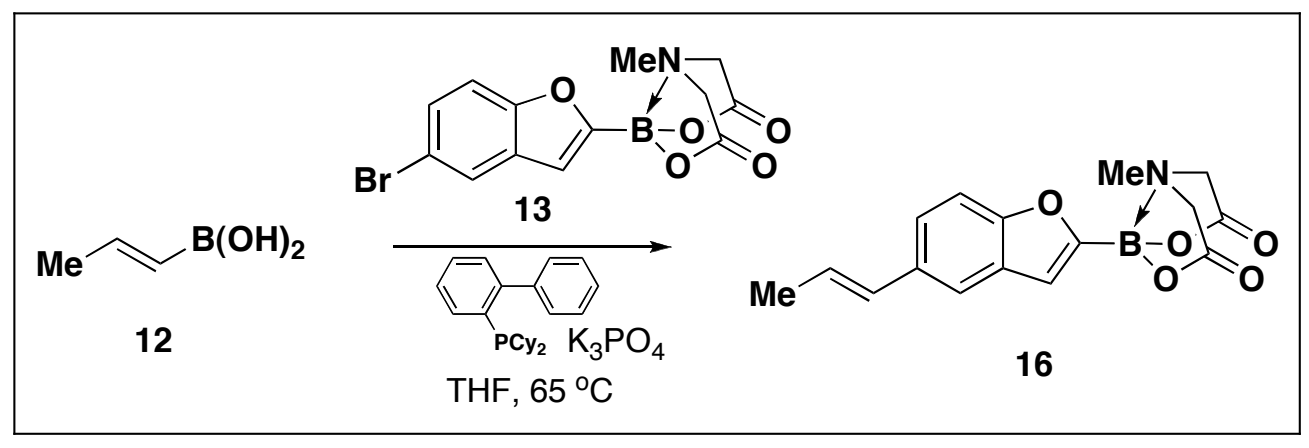

Boronate ester 16. The general procedure for Suzuki-Miyaura coupling reactions (page S14) was followed using $13(352 \mathrm{mg}, 1.00 \mathrm{mmol})$ and $(E)-1$-propenylboronic acid $(144 \mathrm{mg}, 2.00 \mathrm{mmol})$. The product was eluted using a gradient of $\mathrm{Et}_{2} \mathrm{O}: \mathrm{MeCN}$ 10:1 $\rightarrow$ 1:1. The desired product 16 was isolated as a colorless crystalline solid $(251 \mathrm{mg}, 80 \%)$.

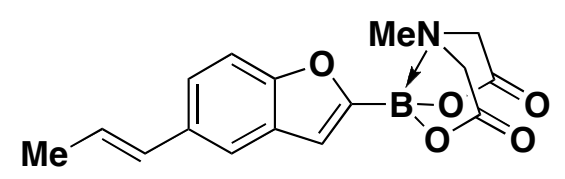

16

TLC (EtOAc)

$\mathrm{R}_{\mathrm{f}}=0.34$, stained by $\mathrm{KMnO}_{4}$

${ }^{1} \mathrm{H}-\mathrm{NMR}\left(500 \mathrm{MHz}, \mathrm{CD}_{3} \mathrm{CN}\right)$

ठ $7.55(\mathrm{~m}, 1 \mathrm{H}), 7.42(\mathrm{~d}, J=8.5 \mathrm{~Hz}, 1 \mathrm{H}), 7.34(\mathrm{dd}, J=8.5 \mathrm{~Hz}, 1 \mathrm{H}), 7.05(\mathrm{~d}, J=1 \mathrm{~Hz}, 1 \mathrm{H}), 6.51$

$(\mathrm{m}, 1 \mathrm{H}), 6.25(\mathrm{dq}, J=16,7 \mathrm{~Hz}, 1 \mathrm{H}), 4.11(\mathrm{~d}, J=17 \mathrm{~Hz}, 2 \mathrm{H}), 3.96(\mathrm{~d}, J=17 \mathrm{~Hz}, 2 \mathrm{H}), 2.69$ (s, $3 \mathrm{H}), 1.85(\mathrm{dd}, J=7,2 \mathrm{~Hz}, 3 \mathrm{H})$.

${ }^{13} \mathrm{C}-\mathrm{NMR}\left(125 \mathrm{MHz}, \mathrm{CD}_{3} \mathrm{CN}\right)$

ठ 169.1, 157.6, 134.0, 131.8, 129.5, 125.5, 123.7, 119.4, 115.8, 112.2, 62.6, 48.1, 18.6.

${ }^{11} \mathrm{~B}-\mathrm{NMR}\left(100 \mathrm{MHz}, \mathrm{CD}_{3} \mathrm{CN}\right)$

ठ 9.8

HRMS (EI+):

Calculated for $\mathrm{C}_{16} \mathrm{H}_{16} \mathrm{O}_{5} \mathrm{NB}(\mathrm{M})^{+}: \quad 313.1122$

Found:

313.1123

IR (thin film, $\mathrm{cm}^{-1}$ )

3008, 2958, 1767, 1711, 1563, 1453, 1336, 1283, 1253, 1175, 1053, 1006, 963, 855. 


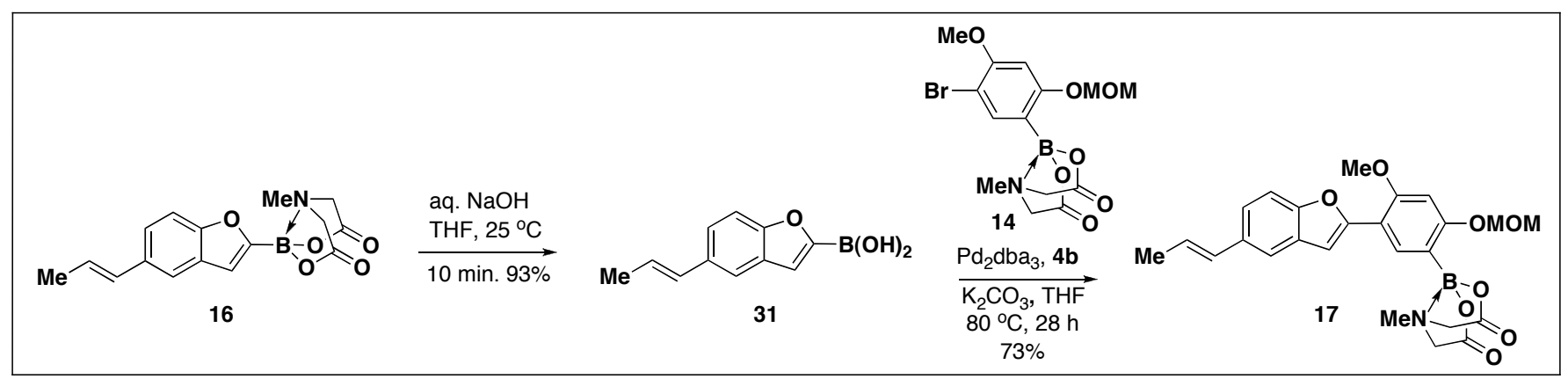

Boronate ester 17. The general procedure for deprotection of boronate esters (S19) was followed using $16(313 \mathrm{mg}, 1.00 \mathrm{mmol})$, and $1 \mathrm{M}$ aq. $\mathrm{NaOH}(3.0 \mathrm{~mL}, 3.0 \mathrm{mmol})$ to afford boronic acid 31 as an off-white solid (188 mg, 93\%); TLC: (EtOAc) $\mathrm{R}_{\mathrm{f}}=0.2$, visualized by UV; HRMS (EI+): Calculated for $\mathrm{C}_{11} \mathrm{H}_{11} \mathrm{O}_{3} \mathrm{~B}$ $(\mathrm{M})^{+}$202.0801, Found 202.0805. Boronic acid $\mathbf{3 1}$ was found to be very sensitive to decomposition upon storage and was therefore used immediately in the next reaction. In a glove box, to a $40 \mathrm{~mL}$ I-Chem vial containing 14 (141 mg, $0.351 \mathrm{mmol}$ ) was added boronic acid 31 (106 mg, $0.526 \mathrm{mmol})$ as a solution in THF (3.15 mL) followed by solid $\mathrm{K}_{2} \mathrm{CO}_{3}(145 \mathrm{mg}, 1.05 \mathrm{mmol})$. To the vial was then added $350 \mu \mathrm{L}$ of a THF catalyst stock solution containing 2-(dicyclohexylphosphino)biphenyl $(0.04 \mathrm{M})$ and $\mathrm{Pd}_{2} \mathrm{dba}_{3}(0.01$ M) which was preincubated at $65{ }^{\circ} \mathrm{C}$ for $30 \mathrm{~min}$. with stirring. The vial was sealed with a PTFE-lined cap, removed from the glove box, and maintained at $80{ }^{\circ} \mathrm{C}$ with stirring for $28 \mathrm{~h}$. The reaction mixture was allowed to cool to $23{ }^{\circ} \mathrm{C}$, and was then passed through a thin pad of silica gel topped with Celite, eluting with a copious volume of $\mathrm{Et}_{2} \mathrm{O}$. The filtrate was concentrated in vacuo and the resulting crude product was adsorbed onto Florisil gel from a MeCN solution. The resulting powder was dry-loaded on top of a silica gel column slurry-packed with $\mathrm{Et}_{2} \mathrm{O}$. The column was flushed with a copious volume of $\mathrm{Et}_{2} \mathrm{O}$; the product was then eluted with $\mathrm{Et}_{2} \mathrm{O}: \mathrm{MeCN}$ 3:1 to yield boronate ester 17 as an off-white solid (123 mg, 73\%).

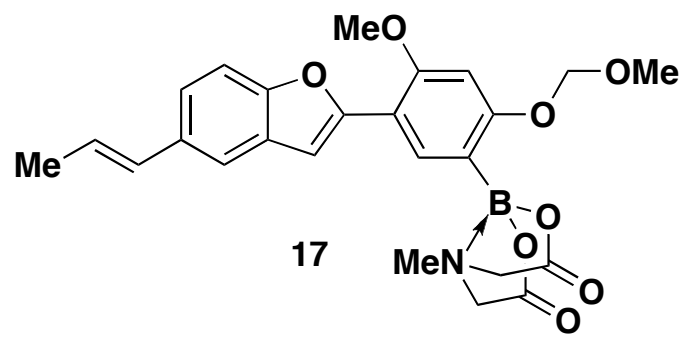

TLC $\left(\mathrm{Et}_{2} \mathrm{O}: \mathrm{CH}_{3} \mathrm{CN} 3: 1\right)$

$\mathrm{R}_{\mathrm{f}}=0.36$, stained by $\mathrm{KMnO}_{4}$

${ }^{1} \mathrm{H}-\mathrm{NMR}\left(500 \mathrm{MHz}, \mathrm{CD}_{3} \mathrm{CN}\right)$

$\delta 8.15(\mathrm{~s}, 1 \mathrm{H}), 7.53(\mathrm{~d}, J=2 \mathrm{~Hz}, 1 \mathrm{H}), 7.44(\mathrm{~d}, J=8.5 \mathrm{~Hz}, 1 \mathrm{H}), 7.29(\mathrm{dd}, J=8.5,2 \mathrm{~Hz}, 1 \mathrm{H}), 7.22$

$(\mathrm{s}, 1 \mathrm{H}), 6.85(\mathrm{~s}, 1 \mathrm{H}), 6.51(\mathrm{dd}, J=16,1.5 \mathrm{~Hz}, 1 \mathrm{H}), 6.26(\mathrm{dq}, J=16,6.5 \mathrm{~Hz}, 1 \mathrm{H}), 5.25(\mathrm{~s}, 2 \mathrm{H})$, $4.11(\mathrm{~d}, J=17 \mathrm{~Hz}, 2 \mathrm{H}), 3.99$ (d, $J=17 \mathrm{~Hz}, 2 \mathrm{H}), 3.99$ (s, 3H), 3.42 (s, 3H), 2.68 (s, 3H), 1.86 (dd, $J=6.5,1.5 \mathrm{~Hz}, 3 \mathrm{H})$.

${ }^{13} \mathrm{C}-\mathrm{NMR}\left(125 \mathrm{MHz}, \mathrm{CD}_{3} \mathrm{CN}\right)$

ठ $169.7,162.5,160.0,154.0,153.8,134.2,133.6,131.9,131.2,125.3,123.0,118.8,113.1,111.4$, $105.4,98.6,95.0,64.5,57.0,56.4,48.4,18.6$. 
${ }^{11} \mathrm{~B}-\mathrm{NMR}\left(100 \mathrm{MHz}, \mathrm{CD}_{3} \mathrm{CN}\right)$

$\delta 12.0$

HRMS (FAB+)

Calculated for $\mathrm{C}_{25} \mathrm{H}_{27} \mathrm{O}_{8} \mathrm{NB}(\mathrm{M}+\mathrm{H})^{+}$: $\quad 480.1830$

Found: $\quad 480.1828$

IR (thin film, $\mathrm{cm}^{-1}$ )

$3009,2959,2911,2850,1768,1710,1605,1575,1501,1446,1368,1337,1299,1267,1193$, 1153, 1139, 1080, 1036, 1008, 964, 859, 816.

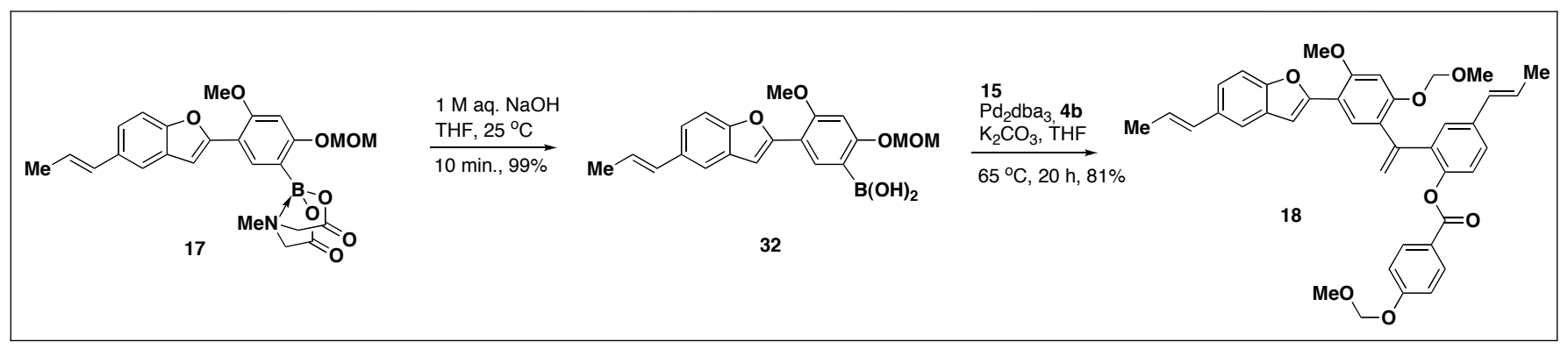

Protected ratanhine 18. A $6 \mathrm{~mL}$ vial equipped with a stir bar was charged with boronate ester 17 (51 mg, $0.106 \mathrm{mmol})$, THF $(1.0 \mathrm{~mL})$, and $1 \mathrm{M}$ aq. $\mathrm{NaOH}(0.32 \mathrm{~mL}, 0.32 \mathrm{mmol})$. The resulting mixture was vigorously stirred for $10 \mathrm{~min}$., then diluted with $0.5 \mathrm{M} \mathrm{pH} 7$ phosphate buffer $(2.0 \mathrm{~mL})$ and $\mathrm{Et}_{2} \mathrm{O}(1.0$ $\mathrm{mL})$. The phases were separated and the aq. phase was extracted once with THF: $\mathrm{Et}_{2} \mathrm{O}$ 1:1 (2.0 mL). The combined organics were dried over $\mathrm{MgSO}_{4}$, filtered, and then concentrated in vacuo. Residual solvent was removed via coevaporation with $\mathrm{PhMe}$, followed by $\mathrm{MeCN}\left(2 \mathrm{X}\right.$ ), and then $\mathrm{CH}_{2} \mathrm{Cl}_{2}$ (2X) (bath temperature maintained at $\left.<30{ }^{\circ} \mathrm{C}\right)$ to yield boronic acid 32 as an off-white solid $(39.2 \mathrm{mg}, 99 \%)$ : TLC (EtOAc) $\mathrm{R}_{\mathrm{f}}=0.53$, visualized by UV; ${ }^{1} \mathrm{H} \mathrm{NMR}\left(400 \mathrm{MHz}, \mathrm{CDCl}_{3}\right) \delta 8.49(\mathrm{~s}, 1 \mathrm{H}), 7.49(\mathrm{~s}, 1 \mathrm{H}), 7.42(\mathrm{~d}, J$ $=8 \mathrm{~Hz}, 1 \mathrm{H}), 7.26(\mathrm{~m}, 1 \mathrm{H}), 7.17(\mathrm{~s}, 1 \mathrm{H}), 6.84(\mathrm{~s}, 1 \mathrm{H}), 6.49(\mathrm{~d}, J=16 \mathrm{~Hz}, 1 \mathrm{H}), 6.20(\mathrm{dq}, J=16,6.4 \mathrm{~Hz}$, $1 \mathrm{H}), 5.77(\mathrm{~s}, 2 \mathrm{H}), 5.35(\mathrm{~s}, 2 \mathrm{H}), 4.03(\mathrm{~s}, 3 \mathrm{H}), 3.55(\mathrm{~s}, 3 \mathrm{H}), 1.90(\mathrm{~d}, J=6.4 \mathrm{~Hz}, 3 \mathrm{H})$; HRMS (TOF ES+): Calculated for $\mathrm{C}_{20} \mathrm{H}_{22} \mathrm{O}_{6} \mathrm{~B}(\mathrm{M}+\mathrm{H})^{+} 369.1509$, Found 369.1515 .

This boronic acid was then quantitatively transferred as a solution in THF to a $6 \mathrm{~mL}$ vial containing 15 (28.5 mg, $0.071 \mathrm{mmol})$ and the solvent was removed in vacuo. In the glove box, to this vial was added solid $\mathrm{K}_{2} \mathrm{CO}_{3}(39.2 \mathrm{mg}, 0.28 \mathrm{mmol}$ ), and a freshly-prepared THF solution (1.06 mL) of 2(dicyclohexylphosphino)biphenyl $(0.008 \mathrm{M})$ and $\mathrm{Pd}_{2} \mathrm{dba}_{3}(0.002 \mathrm{M})$. A stir bar was added and the vial was sealed with a PTFE-lined cap, removed from the glove box, and maintained at $65^{\circ} \mathrm{C}$ with stirring for $20 \mathrm{~h}$. The reaction mixture was then allowed to cool to $23{ }^{\circ} \mathrm{C}$ and passed through a thin pad of silica gel topped with Celite, eluting with a copious volume of EtOAc. The filtrate was concentrated in vacuo, and the resulting crude product was adsorbed onto Florisil gel from a $\mathrm{CH}_{2} \mathrm{Cl}_{2}$ solution. The resulting powder was dry-loaded on top of a silica gel column slurry-packed with hexanes:EtOAc 10:1. The column was eluted with hexanes:EtOAc 10:1 $\rightarrow$ 3:1 to yield 18 as a viscous yellow oil (37.0 mg, 81\%). 
TLC (Hexanes:ethyl acetate 1:1)

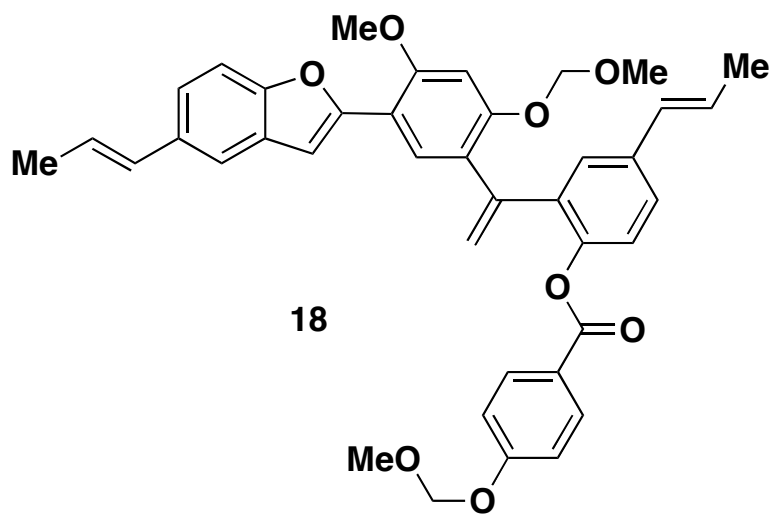

$\mathrm{R}_{\mathrm{f}}=0.47$, visualized by $\mathrm{UV}$

${ }^{1} \mathrm{H}-\mathrm{NMR}\left(500 \mathrm{MHz}, \mathrm{CDCl}_{3}\right)$

$7.76(\mathrm{~s}, 1 \mathrm{H}), 7.65(\mathrm{~d}, J=9 \mathrm{~Hz}, 2 \mathrm{H}), 7.49(\mathrm{~d}, J=2 \mathrm{~Hz}, 1 \mathrm{H}), 7.44(\mathrm{~d}, J=1 \mathrm{~Hz}, 1 \mathrm{H}), 7.31(\mathrm{~d}, J=8.5$

$\mathrm{Hz}, 1 \mathrm{H}), 7.29$ (dd, $J=8.5,2 \mathrm{~Hz}, 1 \mathrm{H}), 7.24(\mathrm{dd}, J=8.5,1.5 \mathrm{~Hz}, 1 \mathrm{H}), 6.99(\mathrm{~s}, 1 \mathrm{H}), 6.98(\mathrm{~d}, J=8.5$

$\mathrm{Hz}, 1 \mathrm{H}), 6.64(\mathrm{~d}, J=9 \mathrm{~Hz}, 2 \mathrm{H}), 6.61(\mathrm{~s}, 1 \mathrm{H}), 6.49(\mathrm{dd}, J=16,1 \mathrm{~Hz}, 1 \mathrm{H}), 6.45(\mathrm{dd}, J=16,1 \mathrm{~Hz}$,

$1 \mathrm{H}), 6.26(\mathrm{dq}, J=16,6.5 \mathrm{~Hz}, 1 \mathrm{H}), 6.20(\mathrm{dq}, J=16,6.5 \mathrm{~Hz}, 1 \mathrm{H}), 5.53(\mathrm{~d}, J=1.5 \mathrm{~Hz}, 1 \mathrm{H}), 5.51(\mathrm{~d}$, $J=1.5 \mathrm{~Hz}, 1 \mathrm{H}), 4.84(\mathrm{~s}, 2 \mathrm{H}), 4.64(\mathrm{~s}, 2 \mathrm{H}), 3.92(\mathrm{~s}, 3 \mathrm{H}), 3.28(\mathrm{~s}, 3 \mathrm{H}), 3.17(\mathrm{~s}, 3 \mathrm{H}), 1.91$ (app d, $J=$ $6.5 \mathrm{~Hz}, 6 \mathrm{H})$.

${ }^{13} \mathrm{C}-\mathrm{NMR}\left(125 \mathrm{MHz}, \mathrm{CDCl}_{3}\right)$

$164.2,160.9,157.2,155.2,152.8,152.5,146.6,144.4,135.7,135.6,132.7,131.8,131.3,130.3$, $130.1,128.8,127.8,125.8,125.3,124.1,124.0,122.8,122.1,121.8,119.2,117.6,114.5,112.9$, $110.6,104.3,98.5,94.4,93.5,55.9,55.8,55.6,18.5,18.5$.

HRMS (TOF ES+)

Calculated for $\mathrm{C}_{40} \mathrm{H}_{39} \mathrm{O}_{8}(\mathrm{M}+\mathrm{H})^{+}: \quad 647.2645$

Found:

647.2642

IR (thin film, $\mathrm{cm}^{-1}$ )

2961, 2928, 2913, 1732, 1606, 1574, 1508, 1448, 1379, 1264, 1243, 1197, 1168, 1151, 1080,

$1065,1002,967$, 


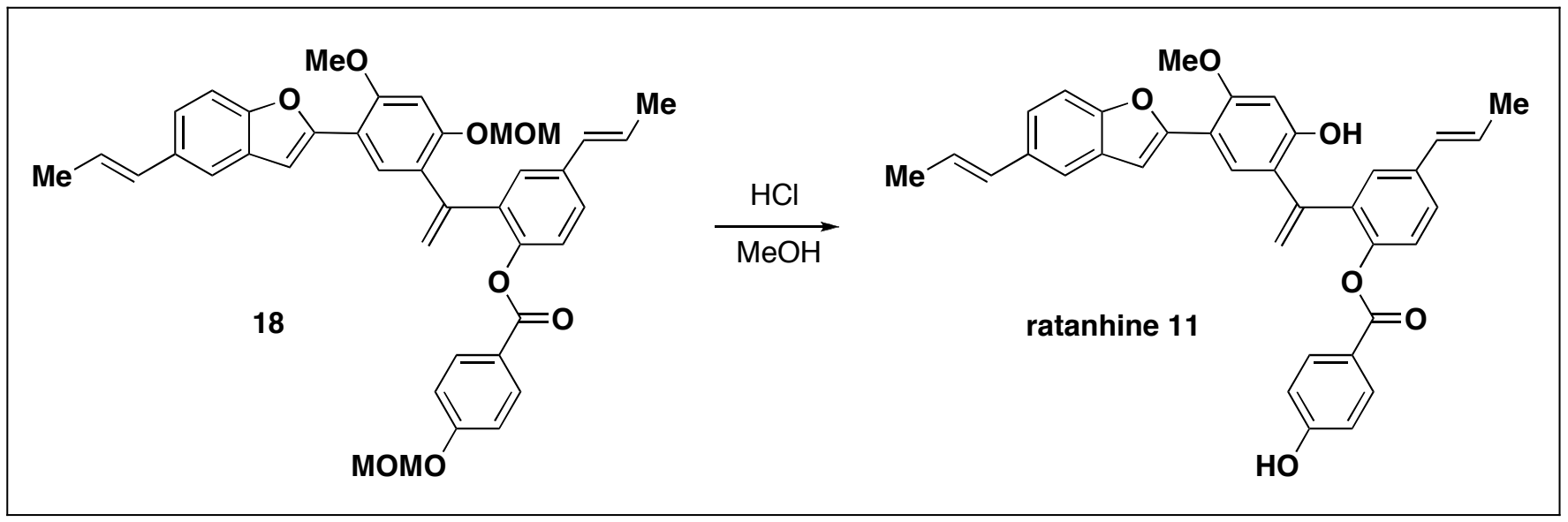

Ratanhine 11. In an unoptimized procedure, a $6 \mathrm{~mL}$ vial equipped with a stir bar was charged with 18 $(27 \mathrm{mg}, 0.042 \mathrm{mmol})$, THF $(0.3 \mathrm{~mL}), \mathrm{MeOH}(0.6 \mathrm{~mL})$, and concentrated $\mathrm{HCl}(12 \mu \mathrm{L})$. The vial was sealed with a PTFE-lined cap and maintained at $65{ }^{\circ} \mathrm{C}$ with stirring for $1 \mathrm{~h}$. The solution was then allowed to cool to $23{ }^{\circ} \mathrm{C}$ and diluted with $\mathrm{H}_{2} \mathrm{O}(1 \mathrm{~mL})$, THF $(1 \mathrm{~mL})$ and $\mathrm{Et}_{2} \mathrm{O}(2 \mathrm{~mL})$. The phases were separated and the aq. phase was extracted repeatedly with EtOAc. The combined organics were concentrated in vacuo and the resulting crude product was purified by preparative HPLC (Waters SunFire Prep $\mathrm{C}_{18}$ OBD 30 x $150 \mathrm{~mm}$ column, Lot \# 168I161701, $25 \mathrm{~mL} / \mathrm{min}$., $\mathrm{H}_{2} \mathrm{O}: \mathrm{MeCN}$ 95:5 $\rightarrow$ 5:95 over 20 min., then $\mathrm{H}_{2} \mathrm{O}: \mathrm{MeCN}$ 5:95 for $15 \mathrm{~min}$; $\mathrm{t}_{\mathrm{R}}=24.84 \mathrm{~min}$ with $\mathrm{UV}$ detection at 325 and $218 \mathrm{~nm}$ ) to yield 11 $(9.6 \mathrm{mg}, 41 \%)$ [ ${ }^{1} \mathrm{H}$ NMR analysis demonstrated that this sample contained a small amount $(\sim 5-10 \%)$ of an unidentified impurity.] An optimized preparative HPLC method was subsequently developed (Waters SunFire Prep $\mathrm{C}_{18}$ OBD 30 x $150 \mathrm{~mm}$ column, Lot \# 168I161701, $33 \mathrm{~mL} / \mathrm{min}$., isochratic $\mathrm{H}_{2} \mathrm{O}: \mathrm{MeCN}$ $20: 80 ; \mathrm{t}_{\mathrm{R}}=21.72 \mathrm{~min}$ with $\mathrm{UV}$ detection at 325 and $218 \mathrm{~nm}$ ) that yielded the pure natural product. ${ }^{1} \mathrm{H}$ $\mathrm{NMR},{ }^{13} \mathrm{C}$ NMR, HRMS, and IR analysis of synthetic 11 were fully consistent with the data reported for the isolated natural product ratanhine (see below), thus confirming the original structure proposed by Arnone and coworkers. ${ }^{16}$

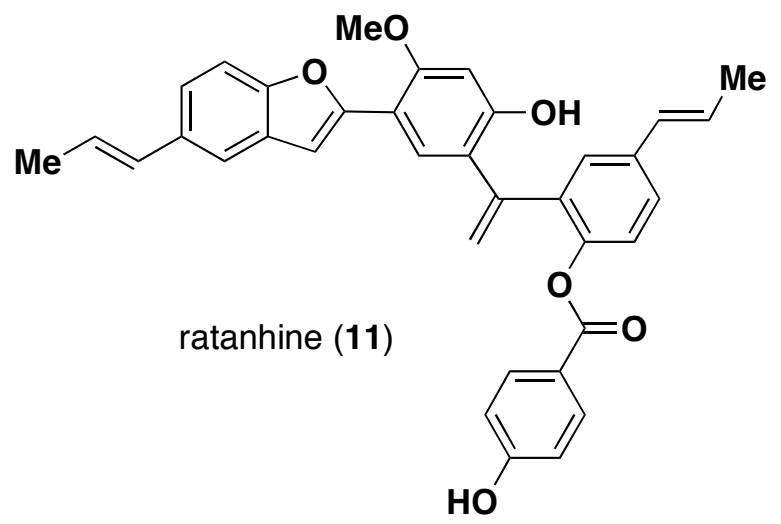

TLC (Hexanes:EtOAc, 1:1)

$\mathrm{R}_{\mathrm{f}}=0.49$, visualized by $\mathrm{UV}$

16 Arnone, A.; Modugno, V.D.; Nasini, G.; de Pava, O.V. Gazetta Chimica Italiana, 1990, 120, 397-401. 
${ }^{1} \mathrm{H}-\mathrm{NMR}\left(500 \mathrm{MHz}, d_{6}\right.$-DMSO)

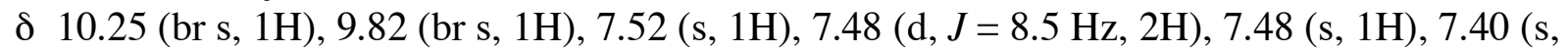
$1 \mathrm{H}), 7.39(\mathrm{~m}, 1 \mathrm{H}), 7.39(\mathrm{~m}, 1 \mathrm{H}), 7.25(\mathrm{~d}, J=8.5 \mathrm{~Hz}, 1 \mathrm{H}), 7.07(\mathrm{~d}, J=8 \mathrm{~Hz}, 1 \mathrm{H}), 7.01(\mathrm{~s}, 1 \mathrm{H})$, $6.59(\mathrm{~d}, J=8.5 \mathrm{~Hz}, 2 \mathrm{H}), 6.47(\mathrm{~s}, 1 \mathrm{H}), 6.47(\mathrm{~d}, J=16 \mathrm{~Hz}, 1 \mathrm{H}), 6.47(\mathrm{~d}, J=16 \mathrm{~Hz}, 1 \mathrm{H}), 6.31(\mathrm{dq}, J$ $=16,7 \mathrm{~Hz}, 1 \mathrm{H}), 6.23(\mathrm{dq}, J=16,7 \mathrm{~Hz}, 1 \mathrm{H}), 5.51(\mathrm{~s}, 1 \mathrm{H}), 5.44(\mathrm{~s}, 1 \mathrm{H}), 3.86(\mathrm{~s}, 3 \mathrm{H}), 1.86(\mathrm{~m}, 3 \mathrm{H})$, $1.86(\mathrm{~m}, 3 \mathrm{H})$.

${ }^{13} \mathrm{C}-\mathrm{NMR}\left(125 \mathrm{MHz}, d_{6}\right.$-DMSO)

d $163.8,162.3,156.8,156.4,152.5,152.1,146.6,142.8,135.3,135.0,132.4,131.7$ (2C), 131.1, $130.0,129.7,127.7,127.4,125.7,125.2,123.7,123.2,121.6,120.7,119.0,118.8,117.5,114.8$ (2C), 110.4, 109.5, 103.3, 99.4, 55.5, 18.3, 18.3.

HRMS (TOF ES+)

Calculated for $\mathrm{C}_{36} \mathrm{H}_{31} \mathrm{O}_{6}(\mathrm{M}+\mathrm{H})^{+}: \quad 559.2121$

Found:

559.2118

IR (thin film, $\mathrm{cm}^{-1}$ )

3344, 1700, 1608, 1591, 1502, 1447, 1267, 1197, 1163, 1101, 1076, 1031, 964, 912.

${ }^{1} \mathrm{H}$ NMR data for natura ${ }^{16}$ and synthetic ratanhine: $\delta_{\mathrm{H}} / \mathrm{ppm}$ (integration)

\begin{tabular}{|c|c|}
\hline $\begin{array}{c}\text { Natural 11 } \\
\left(300 \mathrm{MHz}, d_{6}-\text {-DSO }\right)\end{array}$ & $\begin{array}{c}\text { Synthetic 11 } \\
\left(500 \mathrm{MHz}, d_{6} \text {-DMSO }\right)\end{array}$ \\
\hline $10.22(1 \mathrm{H})$ & $10.25(1 \mathrm{H})$ \\
\hline $9.78(1 \mathrm{H})$ & $9.82(1 \mathrm{H})$ \\
\hline $7.52(1 \mathrm{H})$ & $7.52(1 \mathrm{H})$ \\
\hline $7.51(2 \mathrm{H})$ & $7.48(2 \mathrm{H})$ \\
\hline $7.51(1 \mathrm{H})$ & $7.48(1 \mathrm{H})$ \\
\hline $7.41(1 \mathrm{H})$ & $7.40(1 \mathrm{H})$ \\
\hline $7.39(1 \mathrm{H})$ & $7.39(1 \mathrm{H})$ \\
\hline $7.38(1 \mathrm{H})$ & $7.39(1 \mathrm{H})$ \\
\hline $7.24(1 \mathrm{H})$ & $7.25(1 \mathrm{H})$ \\
\hline $7.07(1 \mathrm{H})$ & $7.07(1 \mathrm{H})$ \\
\hline $7.02(1 \mathrm{H})$ & $7.01(1 \mathrm{H})$ \\
\hline $6.62(2 \mathrm{H})$ & $6.59(2 \mathrm{H})$ \\
\hline $6.50(1 \mathrm{H})$ & $6.47(1 \mathrm{H})$ \\
\hline $6.47(1 \mathrm{H})$ & $6.47(1 \mathrm{H})$ \\
\hline $6.47(1 \mathrm{H})$ & $6.47(1 \mathrm{H})$ \\
\hline $6.31(1 \mathrm{H})$ & $6.31(1 \mathrm{H})$ \\
\hline $6.23(1 \mathrm{H})$ & $6.23(1 \mathrm{H})$ \\
\hline $5.53(1 \mathrm{H})$ & $5.51(1 \mathrm{H})$ \\
\hline $5.46(1 \mathrm{H})$ & $5.44(1 \mathrm{H})$ \\
\hline $3.87(3 \mathrm{H})$ & $3.86(3 \mathrm{H})$ \\
\hline $1.86(3 \mathrm{H})$ & $1.86(3 \mathrm{H})$ \\
\hline $1.86(3 \mathrm{H})$ & $1.86(3 \mathrm{H})$ \\
\hline
\end{tabular}


${ }^{13} \mathrm{C}$ NMR data for natural ${ }^{15}$ and synthetic ratanhine: $\delta_{\mathrm{C}} / \mathrm{ppm}$

\begin{tabular}{|c|c|}
\hline $\begin{array}{c}\text { Natural 11 } \\
\text { (69.2 MHz, } d_{6} \text {-DMSO) }\end{array}$ & $\begin{array}{c}\text { Synthetic 11 } \\
\left(125 \mathrm{MHz}, d_{6}-\mathrm{DMSO}\right)\end{array}$ \\
\hline 163.8 & 163.8 \\
\hline 162.1 & 162.3 \\
\hline 156.7 & 156.8 \\
\hline 156.3 & 156.4 \\
\hline 152.5 & 152.5 \\
\hline 152.0 & 152.1 \\
\hline 146.5 & 146.6 \\
\hline 142.8 & 142.8 \\
\hline 135.3 & 135.3 \\
\hline 134.9 & 135.0 \\
\hline 132.3 & 132.4 \\
\hline $131.7(2 \mathrm{C})$ & $131.7(2 \mathrm{C})$ \\
\hline 131.0 & 131.1 \\
\hline 130.0 & 130.0 \\
\hline 129.7 & 129.7 \\
\hline 127.7 & 127.7 \\
\hline 127.4 & 127.4 \\
\hline 125.6 & 125.7 \\
\hline 125.1 & 125.2 \\
\hline 123.7 & 123.7 \\
\hline 123.1 & 123.2 \\
\hline 121.6 & 121.6 \\
\hline 120.7 & 120.7 \\
\hline 119.0 & 119.0 \\
\hline 118.7 & 118.8 \\
\hline 117.4 & 117.5 \\
\hline $114.8(2 \mathrm{C})$ & $114.8(2 \mathrm{C})$ \\
\hline 110.4 & 110.4 \\
\hline 109.5 & 109.5 \\
\hline 103.3 & 103.3 \\
\hline 99.4 & 99.4 \\
\hline 55.4 & 55.5 \\
\hline 18.2 & 18.3 \\
\hline 18.2 & 18.3 \\
\hline
\end{tabular}

